\title{
Resource Abundance and Economic Growth in China*
}

\author{
Rui Fan ${ }^{\dagger} \quad$ Ying Fang ${ }^{\ddagger} \quad$ Sung Y. Park ${ }^{\S}$
}

\begin{abstract}
This paper studies the resource curse phenomenon in China. The "resource curse" is an important claim that the resource-abundant economies grow at a slower pace than the resource-scarce economies do. There are many recent studies that analyze the resource curse phenomenon theoretically and empirically. However, few papers analyze which socio-economic variables determine the resource curse. This paper is different from the previous studies in three aspects: (i) The city-level data is used; (ii) Using the functional coefficient regression model we can take care of city-specific heterogeneity and, at the same time, analyze the transmission mechanism of the curse of recourses; (iii) We construct a variable to estimate the effect of the diffusion processes of the natural resources among cities in the same province. Our empirical results show that there is no evidence to support the statement of resource curse in China. On the other hand, the level of natural resources in a city imposes a significant positive diffusion effect on the economic growth of neighbor city within the same province.
\end{abstract}

JEL code: O13; O18

Key words: Resource curse; Diffusion effects; Transmission channels; Functional coefficient Model;

*Previous title of this paper was "Diffusion Effects or Curse of Resources? An Evidence from China". The authors would like to thank Zhigang Li, Yiu Por Che, Chun-Chung Au, Ji Kan, and the participants in conferences and seminar in Young Economist Society (YES), Xiamen University, April 3-4, 2010, Brownbag Seminar at WISE, Xiamen University, May 15, 2010, and Chinese Economists Society (CES), Xiamen University, June 19-21, 2010 for many pertinent comments and discussions. However, we retain the responsibility for any remaining errors.

${ }^{\dagger}$ The Wang Yanan Institute for Studies in Economics, Xiamen University, Xiamen, Fujian 361005, China.

¥The Wang Yanan Institute for Studies in Economics, MOE Key Laborary of Econometrics, and Fujian Key Laboratory of Statistical Sciences, Xiamen University, Xiamen, Fujian 361005, China.

${ }^{\S}$ Corresponding Author: Department of Economics, Chinese University of Hong Kong, Shatin, NT, Hong Kong, China. Tel: +852-2609-8001, Fax: +852-2603-5805. Email: sungpark@cuhk.edu.hk. 


\section{Introduction}

Many recent studies try to answer a fundamental question whether natural resource is an important engine of economic growth [Leite and Weidmann, 1999; Papyrakis and Gerlagh, 2004; Rodriguez and Sachs, 1999; Sachs and Warner, 1995, 1997, 1999 among many others]. Their common finding is that natural resource-abundant countries have slower economic growth rates than those of natural resource-scarce economies. This phenomenon is referred to the term "resource curse" in the literature, and it is quite widely accepted. However, it is hard to believe that the natural abundance has the direct effect on the low economic growth rates. Therefore, some recent studies analyze which socio-economic variables do generate the negative correlation between economic growth and natural resource abundance [Angrist and Kugler, 2008; Auty, 1990; Gelb, 1988; Gylfason, 2000; Kronenberg, 2004; Papyrakis and Gerlagh, 2004; Sachs and Warner, 1995 among many oth-

ers]. For examples, Gelb (1988) and Auty (1990) argue that the resource rich countries are likely to pay more attention to the rent-seeking behavior rather than other productive activities. Following Matsuyama's (1992) approach, Sachs and Warner (2001) find that resource-abundant economies put more weights on the natural resource goods rather than manufacturing goods. Eventually, this behavior could keep their economies staying at the low level of economic growth. Gylfason (2000) points out that the level of education is also important factor for the resource curse phenomenon. Kronenber (2004) finds that corruption is the major determinant for the curse of natural resources.

Even though some studies analyze the relationship between economic growth and natural resources and its transmission channels, few consider this problem in a country level, say, many different regions within a country. To our knowledge, Papyrakis and Gerlagh (2007) is the first study analyzing the "resource curse" within a country. They investigate 49 U.S. states and find evidences for the resource curse in U.S. In particular, they find that resource abundance decreases investment, schooling, openness and R\&D expenditure and increases corruption. In the similar 
way, using a panel data, Zhang, Xing, Fan and Luo (2008) study the relationship between resource abundance and regional development in China. They find that Chinese provinces with abundant resources perform worse than their resource-poor counterparts in terms of per capita consumption growth when they consider provinces located inland of China. When they use the whole sample that covers most provinces in China, they cannot support the resource curse in China. Fang, Qi and Zhao (2009) explicitly considers the problem of the "curse of resources" in China. They find that there are no relationship between regional income growth and resource abundance.

Even though some studies, for examples, Papyrakis and Gerlagh (2004, 2007) and Fang, Qi and Zhao (2009), consider the role of the transmission mechanism empirically, their approach has some crucial drawbacks. In order to estimate the effect of transmission mechanism they consider two different regression equations. From the estimates of these two independent regression models they calculate the effect of transmission mechanism. However, since one cannot construct standard errors of these estimates in an usual way, a classical t-test cannot be performed to check whether considered transmission channels are important for the relationship between resource abundance and regional economic growth.

This paper is different from the previous researches in three aspects: (i) Instead of using the province-level data we collect the city-level data and analyze the relationship between resource abundance and regional economic growth. This could provide more interesting and specific features of the relationship; (ii) We use a functional coefficient regression model which turns out quite useful and flexible in our analysis. Using the functional coefficient regression model we can take care of heterogeneity of each city and specify the transmission mechanism between natural resources and the economic growth simultaneously. Thus our model can give more direct interpretation for the role of transmission channels; (iii) Due to China's special governance policy, the diffusion effect of natural resources among cities is of importance and interest for economic and political policies in a particular province. We explicitly construct a variable which represents the 
diffusion process from resource-rich cities to resource-scarce cities using the difference of natural resource and physical distance between two cities.

Our results show that there is no supportive evidence to the "resource curse" phenomenon in city level of China over the period 1997-2005 for the 95 cities. By applying the functional coefficient regression model, we observe the estimated regression coefficients of natural abundance on economic growth of regional economy are significantly positive when the relative scale of manufacturing industry, innovation (R\&D), institutional quality and openness are considered as transmission channels, respectively. Especially, through the channel of manufacture, we find an inverted U-shape relationship between natural resource and economic growth which indicates that one unit of natural resource affects the growth of regional economy differently depending on levels of industrialization. We believe that this result is useful for Chinese policy makers to establish appropriate economic and political policies based on the fact of different degrees of industrialization between inland and coastal regions in China. Moreover, our empirical results for the diffusion effect show that the abundance of natural resources encourages not only the local economic development but also boosts the growth of economy in other cities in the same province, which is consistent with the big-push theory explored by Rosenstein-Rodan (1943). This diffusion phenomenon is significant through the economic transmission channels such as manufacture, innovation, human capital investment and openness.

The next section provides the model that explains the relationship between resource abundance and economic growth and its estimation method. Section 3 offers our empirical results which verify our main proposition that natural resource abundance is an engine for economic development at a city level in China. Section 3 also focuses on transmission channels of natural resources (manufacturing industry, innovation, human capital investment, institutional quality and openness). Finally, conclusions are followed in Section 4. 


\section{The Model}

\subsection{Basic Model}

Most empirical studies for analyzing the resource curse consider the linear empirical growth regression model. We start with the basic linear regression model specification:

$$
G_{i}=\alpha_{0}+\alpha_{1} \ln Y_{1990, i}+\alpha_{2} \operatorname{mining}_{i}+z_{i}^{\prime} \xi+u_{i}
$$

where $G_{i}$ denotes the growth rate of income per capita of a city $i$ from 1997 (initial period) to 2005, that is, $G_{i}=\ln \left(Y_{2005, i} / Y_{1997, i}\right), Y_{1990, i}$ is the initial income of a city $i$ in 1990, mining is $_{i}$ the average fraction of workers who are in mining industries at a city $i$ from 1997 to 2005, $z_{i}$ and $\xi$ are the vector of other demographic variables and its corresponding parameter vector, respectively, and $u_{i}$ denotes the disturbance term.

Although the regression model (1) is frequently used and useful to analyze the resource curse phenomenon, it does not tell us which factors are important to explain the partial effect of $\operatorname{mining}_{i}$ on $G_{i}$, i.e., transmission channels that links the line between economic growth and natural resource abundance. Papyrakis and Gerlagh $(2004,2007)$ propose a simple method to answer this question. They consider an additional regression equation given by

$$
z_{1, i}=\beta_{0}+\beta_{1} \ln Y_{1990, i}+\beta_{2} \operatorname{mining}_{i}+\bar{z}_{i}^{\prime} \bar{\xi}+\mu_{i}
$$

where $z_{1, i}$ is a variable in $z_{i}$, which is believed to be a link variable between the income growth rate and resource abundance, $\bar{z}_{i}$ denotes all variables in $z_{i}$ except for $z_{1, i}, \bar{\xi}$ is $\xi$ excluding $\xi_{1}$ and $\mu_{i}$ denotes a random disturbance term. One can substitute $z_{1, i}$ of (2) into (1) and obtain

$$
G_{i}=\left(\alpha_{0}+\xi_{1} \beta_{0}\right)+\left(\alpha_{1}+\xi_{1} \beta_{1}\right) \ln Y_{1990, i}+\left(\alpha_{2}+\xi_{1} \beta_{2}\right) \operatorname{mining}_{i}+\bar{z}_{i}^{\prime}\left(\alpha_{2}+\xi_{1} \bar{\xi}\right)+\epsilon_{i},
$$

where $\epsilon_{i}=\xi_{1} \mu_{i}+u_{i}$. In equation (3), $\alpha_{2}$ is the direct effect of natural resources on growth, $\xi_{1} \beta_{2}$ is the indirect effect of natural resources on growth through $z_{1, i}$. In this way, Papyrakis and Gerlagh 
(2004) take care of the 'indirect effect' of the resource abundance on growth rate based on (3). However, it is clear that parameters in (3) cannot be identified. Thus in order to specify the direct and indirect effects they need to estimate (1) and (2) at the same time. One major problem of the above method is that one cannot obtain the standard error of the indirect effect. Thus one cannot perform a simple inference procedure whether the indirect effect is statistically significant. And, moreover, the suggested method is quite ad-hoc to study the transmission channels.

It is worth noting that $z_{1, i}$ in (2) is determined by the parameters, $\beta_{0}, \beta_{1}$ and $\beta_{2}$ conditional on the covariates. Thus the above (3) can be written by a general form

$$
G_{i}=\phi_{0}\left(z_{1, i}\right)+\phi_{1}\left(z_{1, i}\right) \ln Y_{1990, i}+\phi_{2}\left(z_{1, i}\right) \operatorname{mining}_{i}+\bar{z}_{i}^{\prime} \bar{\xi}\left(z_{1, i}\right)+\epsilon_{i}
$$

where $\phi_{k}(\cdot), k=0,1,2$ and $\bar{\xi}(\cdot)$ are functional coefficients. The model (4) is known as the functional coefficient regression model in the literature. This model has at least two advantages for studying the relationship between natural resources and economic development: (i) The functional coefficient model explicitly incorporates the indirect effect in the model, for example, $\phi_{2}\left(z_{1, i}\right)$ represents the causal relationship between natural resources and the grow rate of income is affected by some index variable $z_{1, i}$. Thus estimation procedure for two regression models (1) and (2) is not needed; (ii) As we mentioned before, the linear regression model (1) is frequently used in the empirical growth literature. However, such linear specification is due to the assumption of identical aggregate production function of each country (Mankiw, Romer and Weil (1992)). This homogeneity assumption is hard to be implemented in the real world. However, the coefficients in (4) are different in each country depending on the index variable $z_{1, i}$. Thus it can take care of the city-specific heterogeneity within the model (Durlauf, Kourtellos and Minkin (2001)). With the above reasons we use (4) to analyze the relationship between natural resource abundance and regional economic growth with transmission channels. However, one drawback of the above model is the non-identification problem for the direct and indirect effects separately. This can be taken care of, if possible, assuming a flexible parametric function. However, in this paper, we do not 
consider this functional specifications to identify the direct and indirect effects, but we estimate $\phi_{i}\left(z_{1, i}\right), i=0,1,2$ using non-parametric estimation methods.

\subsection{Diffusion effect}

Since the local government in a province has an independent right for the distribution of economic resources including natural resources the interacting behavior among cities in the same province could provide useful information for making policy decisions. Thus it is of interest to see how the economic growth rate of a city is affected by the resource abundance of her neighborhood. For the spill-over effect, Fang, Qi and Zhao (2009) consider the following linear regression model

$$
G_{i}=\alpha_{0}+\alpha_{1} \ln Y_{1990, i}+\alpha_{2} \operatorname{mining}_{i}+\alpha_{3} D_{i}+z_{i}^{\prime} \xi+u_{i}
$$

where $D_{i}$ is a dummy variable, i.e., $D_{i}=1$ if city $i$ locates in the province that contains top 10 resource abundant cities out of 96 cities. They argue that there exists a spill-over effect if $\hat{\alpha}_{3}$ is significant. However, it is not quite clear whether $\alpha_{3}$ represents the spill-over effect since $D_{i}$ is nothing but the province dummy variable. Positive significance of $\hat{\alpha}_{3}$ only tells us that the province in which are resource abundant cities yields higher regional income growth. Thus we can say that $D_{i}$ may not represent diffusion processes among cities in the same province.

For the diffusion effect we may want to check whether "because resource-rich cities in my province are my neighbors, my city is better-off" is true. In order to define the variable that measures the diffusion of natural resource we need to consider the following two things. At first, we need to define the "direction" of the diffusion. The diffusion effect between two cities can be categorized by uni-directional or bi-directional diffusion effect. For simplicity, we assume that only resource-rich cities influence resource-poor cities. However, when two cities in the same neighborhood have similar amount of natural resource, the diffusion process can be bi-directional one. Secondly, we also need to define the "neighborhood" carefully. Denote $c_{m k}$ by a $m$-th city 
located in $k$-th province, $m=1,2, \cdots, M_{k}$ and $k=1,2, \cdots, K$. Since provinces are entitled with relatively independent distribution rights in natural resource, we can set the maximum boundary of neighborhood of $m$-th city in $k$-th province by the physical boundary of $k$-th province, say, $\mathcal{P}_{k}$. For each city $m$ in province $k, c_{m k}$, we can construct a ball, $\mathcal{B}_{m k} \in \mathcal{P}_{k}$, which represents the neighborhood of a city $c_{m k}$. Then for each province $k$ we can define a variable that represents the spill-over phenomenon from city $c_{j k}$ to $c_{m k}$ for $j \neq m$

$$
U U_{m} \equiv U_{m k}=\sum_{\left.j \in\left\{1,2, \cdots, M_{k}\right\} \backslash m\right\}}\left[\omega_{j}\left(R_{j}^{k}-R_{m}^{k}\right) \mathbf{1}_{\left\{R_{j}^{k}>R_{m}^{k}\right\}} \mid c_{j k} \in \mathcal{B}_{m k} \subseteq \mathcal{P}_{k}\right],
$$

where $\omega_{j}$ is a distance-based weight given by $\omega_{j}=\left(1 / \operatorname{dist}_{m j}\right) /\left(\sum_{j}\left(1 / \operatorname{dist}_{m j}\right)\right)$ in which dist ${ }_{m j}$ denotes a distance between cities $m$ and $j$ based on their longitudes and latitudes, $R_{j}^{k}$ denotes natural resource abundance at city $j$ in province $k$, and $\mathbf{1}_{\{\cdot\}}$ is the indicate function. The diffusion variable $U_{m k}$ is nothing but a (asymmetrically) weighted average of difference in natural resource abundance between two cities with pre-specified uni-direction. It can be easily extended to bidirectional weighted function by substituting $\mathbf{1}_{\left\{R_{j}^{k}>R_{m}^{k}\right\}}$ by $\mathbf{1}_{\left\{R_{j}^{k}-R_{m}^{k}>\kappa\right\}}$ for some constant $\kappa$. Note that the mixed spatial autoregressive model can be also considered for the above model specification. The weight matrix of the spatial autoregressive model can be specified using rank information of natural resource abundance. However, it is relatively hard to estimate the mixed spatial autoregressive model due to some computational burdens and endogeneity problem. Thus we use $U U_{m}$ to estimate the diffusion effect in this paper.

\subsection{Model Estimation}

For our empirical analysis we consider the functional coefficient model (4) with an additional covariate $U_{m k}$ in (6):

$$
G_{i}=\phi_{0}\left(z_{1, i}\right)+\phi_{1}\left(z_{1, i}\right) \ln Y_{1990, i}+\phi_{2}\left(z_{1, i}\right) \operatorname{mining}_{i}+\phi_{3}\left(z_{1, i}\right) U U_{i}+\bar{z}_{i}^{\prime} \bar{\xi}\left(z_{1, i}\right)+\epsilon_{i} .
$$


For the estimation methodology, as suggested by Fan and Gijbels (1996), one can estimate the coefficient functions $\left\{\phi_{j}(\cdot)\right\}$ using the local linear regression method from observation $\left\{Z_{i}, \mathbf{X}_{i}, Y_{i}\right\}$, where $\mathbf{X}_{i}=\left(X_{i 1}, \cdots, X_{i p}\right)^{\prime}$. Assuming $\phi_{j}(\cdot)$ has a continuous second derivative, $\phi_{j}(\cdot)$ can be approximated locally at $z_{0}$ by a linear function $\gamma_{j}(z) \approx \phi_{j}+b_{j}\left(z-z_{0}\right)$. The local linear estimator, $\left\{\left(\hat{\phi}_{j}, \hat{b}_{j}\right)\right\}$, minimizes the sum of weighted squares

$$
\sum_{i=1}^{n}\left[Y_{i}-\sum_{j=1}^{p}\left\{\phi_{j}+b_{j}\left(Z_{i}-z_{0}\right)\right\} X_{i j}\right]^{2} K_{h}\left(Z_{i}-z_{0}\right),
$$

where $K_{h}(\cdot)=h^{-1} K(\cdot / h), K(\cdot)$ denotes a kernel function and $h>0$ is a bandwidth. Then the local linear estimator at $z_{0}$ can be easily calculated by

$$
\hat{\phi}_{j}\left(z_{0}\right)=\sum_{k=1}^{K} K_{n, j}\left(Z_{k}-z_{0}, \mathbf{X}_{k}\right) Y_{k},
$$

where

$$
K_{n, j}(z, \mathbf{x})=e_{j, 2 p}^{\prime}\left(\tilde{\mathbf{X}}^{\prime} W \tilde{\mathbf{X}}\right)^{-1}\left(\begin{array}{c}
\mathbf{x} \\
z \mathbf{x}
\end{array}\right) K_{h}(z)
$$

$e_{j, 2 p}$ is the $2 p \times 1$ unit vector with 1 at $j$-th element, $\tilde{\mathbf{X}}$ denotes an $n \times 2 p$ matrix with its $i$-th row $\left(\mathbf{X}_{i}^{\prime}, \mathbf{X}_{i}^{\prime}\left(Z_{i}-z_{0}\right)\right)$ and $W=\operatorname{diag}\left\{K_{h}\left(Z_{1}-z_{0}\right), \cdots, K_{h}\left(Z_{n}-z_{0}\right)\right\}$. For the selection of bandwidth $h$, there are some techniques in the non-parametric statistics literature, for example, Ruppert, Sheather and Wand (1995) and Fan and Gijbels (1996) among others. In this paper we use a boundary kernel suggested by Dong and Jiang (2000) to take care of the boudary problem in non-parametric estimation procedure. Their kernel function has three different forms depending on the data. In the central region of the data the kernel function is given by the Epanechnikov kernel, $K(z)=0.75\left(1-z^{2}\right) I(|z| \leq 1)$. For both tail parts, boundary kernels are considered to deal with the boundary problem.

One crucial drawback of the above method is that all slope functional coefficients have the same degree of smoothness since they depend only on one bandwidth parameter, $h$. Thus if $\left\{\phi_{j}(\cdot)\right\}$ have difference degrees of smoothness, the above estimators are sub-optimal. In reality, it is always 
possible that each $\phi_{j}(\cdot)$ may have different degree of smoothness. In order to deal with this problem, we adopt a two-step estimation method proposed by Fan and Zhang (1999). Without loss of generality, let us consider the estimation for the $\phi_{p}(\cdot)$ of $\phi_{j}(\cdot), j=1,2, \cdots, p$. In the first step, the initial (first) estimates of $\left\{\phi_{j}(\cdot)\right\}, j=1,2, \cdots, p-1$ are estimated using small enough bandwidth $h$, which ensures the bias of the estimator is small. From these estimates one can obtain the partial residual,

$$
\hat{\epsilon}_{i,-p}=G_{i}-\hat{\phi}_{1}(z) X_{i 1}-\cdots-\hat{\phi}_{p-1}(z) X_{i, p-1} .
$$

In the second step one solves the following local cubic problem

$$
\min _{a_{p}, b_{p}, c_{p}, d_{p}} \sum_{i=1}^{n}\left[\hat{\epsilon}_{i,-p}-\left(a_{p}+b_{p}\left(Z_{i}-z_{0}\right)+c_{p}\left(Z_{i}-z_{0}\right)^{2}+d_{p}\left(Z_{i}-z_{0}\right)^{3}\right) X_{i p}\right]^{2} K_{h_{2}}\left(Z_{i}-z_{0}\right),
$$

where $h_{2}$ denotes the second step bandwidth. In the above estimation procedure the choice of the first bandwidth does not affect the final result substantially. Fan and Zhang (1999) show that the two-step estimator has the optimal rate of convergence for the asymptotic mean squared errors, and it always yields better performance than the classical local least square estimator does. In this paper we use the least squares cross-validation method to choose the optimal bandwidth, $h_{2}$, in the second step estimation procedure [Härdle and Marror (1985) and Härdle, Hall and Marror (1992)].

\section{Empirical Results}

\subsection{Data}

We employ the data from volumes of Chinese Statistical Yearbooks and World Bank Report (2006). The GDP growth rates and other variables for 95 main cities in China are constructed using the data from 1997 to 2005 . Note that the GDP of these 95 cities contributed for $47.7 \%$ of the national GDP in 1995. Figure 1 plots locations and resource abundance of all cities.

[Figure 1] 
We consider five transmission variables: (i) manufacture: an average ratio of value of the manufacturing industry production to the local GDP from 1997 to 2005; (ii) R\&D: the ratio of R\&D related workers to the local population; (iii) teacher (human capital investment): an average percentage of the number of teachers from primary schools, middle schools and universities in the local population; (iv) court (institutional quality): confidence in court; (v) FDI (openness): the ratio of usage of foreign direct investment (FDI) to the local GDP. ${ }^{1}$

Since the appropriate proxy for the abundance of natural resources is essential to the analysis of this paper, it is necessary to discuss how we obtain sufficient information about natural resources on the city level in China. Conventionally, many previous empirical studies provide three options for the measurement of natural resources: natural resource production, natural resource reserves and exports of primary products. However, these options are highly restricted for our study since they are incomplete and limited to access. It is worth stressing that endogeneity is a potential problem in all these options. For example, Stijns (2005) argues that it is possible that reserves data for natural resources depend on economic growth because rich countries are able to investigate their ground longer and in more efficient ways. This paper does not attempt to discuss this possible problem. Alternatively, we use the fraction of mining workers to the total local population to capture resource abundance. This measurement includes nearly all natural resource industries such as oil, coal, and nonferrous metal. Given the availability of the data, we believe that our chosen proxy represents resource abundance as close as possible.

\subsection{Empirical Results}

In case of the provincial level data, Zhang et.al. (2008) show that per capita consumption growth rates of resource-abundant provinces are lower than those of resource-poor counterparts. Since the

\footnotetext{
${ }^{1}$ Usually, openness is measured by the ratio of export and import to GDP. However, due to the limitation of city level data, we use the ratio of usage of FDI to the local GDP to measure "openness".
} 
sample size of provincial data is relatively small they used a pooled regression model to analyze the resource curse in China. In this paper we consider city-level data to study the curse of resource phenomenon in China. Due to the relatively large sample size of the city level data, our study could provide more trustable results for the curse of resources phenomenon in China. Moreover, we also study how the resource abundance of a city affects its neighbor cities' regional economic growth through different transmission channels.

At first, we start with simple linear regression models to check the existence of the resource curse and diffusion effects. We consider six regression models that are special cases of the following model

$$
G_{i}=\alpha_{0}+\alpha_{1} \text { Mining }_{i}+\alpha_{2} \text { Dlandlock }_{i}+\alpha_{3} \text { Dspecial }_{i}+\alpha_{4} \text { Xinter }_{i}+\alpha_{5} \log Y_{1990, i}+\alpha_{6} U U_{i}+\epsilon_{i}
$$

where Dlandlock ${ }_{i}$ is a dummy variable for a coastal city and Dspecial ${ }_{i}$ denotes a dummy variable representing a municipality directly under the government or a special economic zone or a capital of the province, Xinter denotes Dlandlock $_{i} \times \log Y_{1990, i}$ which also used in Sachs and Warner (1995), and $\log Y_{1990, i}$ is the logarithm of GDP per capita in $1990 .^{2}$ The estimation results for six models are reported in Table 1.

[Table 1]

From Table 1 it is clear that estimated coefficients of Mining $_{i}$ are positive, but they are insignificant except for M6 that includes natural resource variable, Mining ${ }_{i}$, and spatial diffusion variable, $U U_{i}$, at the same time. It turns out that $\operatorname{Mining}_{i}$ and $U U_{i}$ are both positive and significant. These results support that resource curse phenomenon does not exist, and a positive diffusion effect among cities exists in China. However, the above linear regression models cannot shed some lights on transmission channels that link the line between economic growth and natural resources. In this paper, we

\footnotetext{
${ }^{2}$ Since China's economic system reform took off in nearly all big cities in 1990, we set 1990 as the initial GDP per capita year.
} 
analyze that natural resources are associated with not only economic growth but also some other important economic channels such as manufacturing activities, human capital and openness of the economy. Moreover, the above models impose quite strong homogeneity assumption, for example, each city has the identical production technology. This assumption obviously weakens the validity of the empirical results since it is hard to believe each city has the same production function.

We now turn to the functional coefficient model discussed in Section 2:

$$
G_{i}=\phi_{0}\left(z_{1, i}\right)+\phi_{1}\left(z_{1, i}\right) \ln Y_{1990, i}+\phi_{2}\left(z_{1, i}\right) \operatorname{Mining}_{i}+\phi_{3}\left(z_{1, i}\right) U U_{i}+\bar{z}_{i}^{\prime} \bar{\xi}\left(z_{1, i}\right)+\epsilon_{i},
$$

where $z_{1, i}$ is a transmission variable that is commonly used in the literature such as manufacturing activities, R\&D, human capital investment, institutional quality and openness (Gylfason, 2001; Matsuyama, 1992; Papyrakis and Gerlagh, 2004, 2007; Sachs and Warner, 1999, 2001). Since dummy variables in (8) are insignificant we do not include dummy variables in (9).

We estimate equation (9) with various transmission channels that affect the relationship between resource abundance and the growth of regional economy. As we mentioned before, coefficients of all the variables in our model are varying based on different values of a particular transmission channel, which is different from the classical regression analysis. These varying coefficient estimates help us determine which channels are crucial in the relationship of resource and economic growth. More interestingly, it also tells us precisely that how much influence the channels have on the association of natural resource and local economy.

[Figure 2]

Figure 2 shows the estimation results when the relative scale of manufacturing industry is se-

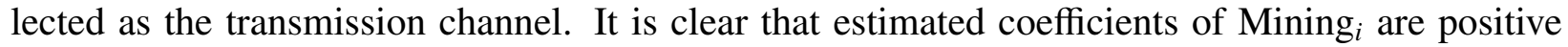
over all range of (log) manufacturing industry. In other words, the result shows that there is no resource curse phenomenon using the city-level data. Moreover, it shows an inverted U-shape which 
indicates that the unit increase of natural resource affects regional economic growth differently depending on levels of industrialization. ${ }^{3}$ One possible explanation for this result might be related with industrialization processes in China. It is commonly accepted that China started its first stage of national industrialization revolution in 1970s and entered into the second stage in the middle 90s of last century. From 1995 to 2004, most local governments accelerated their industrialization processes by optimizing and upgrading the industrial structure. This national-wide development of industrial structure ensures more efficient usage of the natural resources as the raw material inputs. Thus it reduces the dependence of economic growth upon demand for natural resource (Wu, Cheng and Wang (2005)). However this tremendous progress of industrialization does not happen equally to coastal and inland regions. In 2004, the top ten provinces enjoying high degree of industrialization are: Shanghai, Beijing, Tianjin, Guangdong, Zhejiang, Jiangsu, Shandong, Liaoning, Fujian and Shanxi. Except for Shanxi, the other nine provinces belong to coastal regions in China. Moreover, most of under-industrialized provinces are located at inland regions such as Guizhou, Tibet, Gansu and Sichuan (Chen, Huang and Zhong (2006)). As shown in Table 2, ${ }^{4}$ note that according to our estimation results estimated coefficient of Mining $_{i}$ decreases from the highest value 3.758 gradually to 2 as industrialization indicator $\log$ (manufacture) increases from -3 to -2 . When $\log$ (manufacture $)$ is above -2 , estimated coefficient continuously dipped back down to be insignificant even though it is still positive. From our original data, we can find most of highly industrialized cities with $\log$ (manufacture) greater than -2 belong to coastal regions in China, such as Qingdao (-1.82), Shanghai (-1.81), Harbin (-1.66) and Shenzhen (-0.74). For these cities, the positive association between natural resource and local economic growth are given by $1.73,1.72$, 1.45 and 0.32 for Qingdao, Shanghai, Harbin and Shenzhen, respectively, which are quite lower than those of cities with lower level of industrialization.

\footnotetext{
${ }^{3}$ It is common in the literature that the ratio of manufacturing-industry production to the GDP can be considered as a measure for the level of industrialization.

${ }^{4}$ To conserve space we do not report all the results for other four transmission channels but these can be obtained from us on request.
} 
Figure 2 also shows that there is a positive diffusion effect when we take $\log ($ manufacture) as our transmission variable, and moreover, the positive effect declines with the relative scale of manufacturing industry. It is worth stressing that the diffusion variable measures how much the objective city is benefited from its neighbor cities that are richer in abundance of natural resources within the same province. Clearly, our results suggest that resource-richer cities would benefit its neighbor cities depending on the degree of industrialization of neighbor cities. Specifically, when $\log ($ manufacture $)$ is less than -3.6 , its effects are higher than 0.02 . This result is consistent with the nature of a city's process of industrialization. As we described above, under-industrialized cities are likely to depend more on the resource input due to the non-optimized industrial structure. For example, $\log ($ manufacture) of Tianshui (in Gansu province), Leshan (in Sichuan province) and Changde (in Hunan province), which come from inland regions, are -3.15, -3.06 and -3.65, respectively. Comparing with the highly industrialized cities, GDP growth of these cities are generated more by natural resources from neighbor cities. Moreover, this diffusion phenomenon can also be of importance to the China's provincial policy since local government has relatively independent rights in administration and distribution of economic resources.

Figures 3 and 4 show results in which $R \& D$ and human capital investment are considered as transmission channels, respectively. Note that $R \& D$ is obtained by the ratio of $R \& D$ related workers to the local population, and human capital investment is measured by the ratio of the number of teachers from primary schools, middle schools and universities to the local population. In Figure 3, estimated coefficients of Mining $_{i}$ are significantly positive and have an inverted U-shape with respect to the logarithm of $R \& D$. We can say that a city with high value of $R \& D$ is likely to have industries with high technology which are the main engine for the local economic growth. Note that a city that has new and high technology industries tends to have developed industrial structure. Thus natural resource contributes relatively less to the local growth rate when R\&D investment is high. However, estimated effect of Mining $_{i}$ is insignificant when we consider log(teacher) as 
transmission channel (Figure 4).

[Figure 3]

[Figure 4]

Regarding economic interplay among neighbor cities, there is a positive evidence that natural resource abundant cities give benefit to their neighbor cities as shown in Figures 3 and 4. Particularly, it is significant when the values of $\log (R \& D)$ and $\log ($ teacher $)$ are high.

Another indirect transmission channel has been identified in many recent literatures is institutional quality. For example, Leite and Weidmann (1999) claim abundant natural resources increase corruption, and Torvik (2002) indicate that rent seeking behavior can be one major source of channels of resource curse. Figure 5 shows the results when we consider institutional quality as the transmission variable. There is a strong positive relationship between natural resource abundance and local GDP growth. Especially, when the level of institution quality is higher than 0.8, natural resource abundance has high degree of positive effects on the local economy. This clearly shows that high level of institutional quality helps to improve the economic efficiency by creating a sound environment for economic security and development. That is, with high degree of institutional quality, an unit of natural resource may contribute to a rapid increase in local GDP growth due to the decrease of corruption, expropriation and rent-seeking activities. As for diffusion effect, the result shows the positive diffusion effect but it is not statistically significant.

[Figure 5]

Finally, Figure 6 provides another evidence against the statement of resource curse phenomenon in China. To get this result, openness has been taken as the transmission variable. It is clear to see 
that coefficient of Mining $_{i}$ is significantly positive in all the range of $\log (F D I)$ which indicates the level of a city's openness in our case. Moreover, there is significant positive diffusion effect.

[Figure 6]

\section{Conclusion}

Many studies have widely accepted that there is a negative relationship between natural resource abundance and economic growth. Moreover, it is known that some socio-economic variables can affect this negative correlation as transmission channels. However, few empirical studies test this phenomenon topic in a country level. Even though some recent studies employ the state or province-level data to test resource curse phenomenon and analyze its transmission mechanism empirically, it seems that their models are not flexible enough and, at the same time, there are some drawbacks of their inference procedures.

In this paper, we use the functional coefficient regression model to examine whether such phenomenon exists in China and, at the same time, which transmission channels are of importance to link the line of economic development and natural resources. Functional coefficient regression model is quite useful and flexible in our analysis. It can take care of heterogeneity of each city and allow us to specify the transmission channels between natural resources and economic development.

Based on 95 cities in China from 1997 to 2005, we find that there is no resource curse phenomenon in China, and transmission channels that explain the positive association between natural resource and economic growth are found to be relative scale of manufacturing industry, R\&D investment, institutional quality and openness. Especially, an inverted U-shape of the estimated functional regression coefficients of manufacturing industry indicates that levels of industrialization is of importance to determine how much the natural resource abundance affects the local economic 
development. Moreover, the results show that abundance of resources in one city have a positive impact to its neighbor city's economy within the province through various economic transmission channels such as relative scale of manufacturing industry, R\&D, human capital investment and openness. 


\section{References}

Alexeev, M., and R. Conrad (2009): "The elusive curse of oil," The Review of Economics and Statistics, 91, 586-598.

Angrist, J. D., And A. D. Kugler (2008): "Rural Windfall or a New Resource Curse? Coca, Income, and Civil Conflict in Colombia," The Review of Economics and Statistics, 90, 191215.

Auty, R. M. (1990): Resource-Based Industrialization: Sowing the Oil in Eight Developing Countries. Oxford University Press, New York.

Chen, J., Q. Huang, and H. Zhong (2006): "The synthetic evaluation and analysis on regional industrialization," Economic Research (Jingji Yanjiu), 6, 4-15.

Dong, J., AND R. JiANG (2000): “A boundary kernel for local polynomial regression,” Communications in Statistics - Theory and Methods, 29, 1549-1558.

Durlauf, S. N., A. Kourtellos, and A. Minkin (2001): “The local Solow growth model,” European Economic Review, 45, 928-940.

FAn, J., ANd I. GiJBels (1996): Local Polynomial Modelling and Its Applications. Chapman and Hall, London.

FAN, J., AND W. Zhang (1999): "Statistical estimation in varying coefficient models," The Annals of Statistics, 27, 1491-1518.

FANG, Y., L. QI, AND Y. ZhaO (2009): “The ”Curse of Resources” revisited: a different story from China," Working Paper.

Gelb, A. H. (1988): Windfall Gains: Blessing or Curse? Oxford University Press, New York. 
Gylfason, T. (2001): “Natural resources, education, and economic development," European Economic Review, 45, 847-859.

Hardle, W., P. Hall, and J. S. Marron (1992): "Regression smoothing parameters that are not far from their optimum," Journal of the American Statistical Association, 87(417), 227-233.

Hardle, W., and J. S. Marron (1985): “Optimal bandwidth selection in nonparametric regression function estimation," The Annals of Statistics, 13, 1465-1481.

Kronenberg, T. (2004): “The curse of natural resources in the transition economies," Economics of Transition, 12(3), 399-426.

Leite, C., and J. Weidmann (1999): “Does mother nature corrupt? Natural resources, corruption, and economic growth,” IMF Working Paper No. 99/85, International Monetary Fund, Washington, DC.

Mankiw, N. G., D. Romer, and D. N. WeIL (1992): “A contribution to the empirics of economic growth," The Quarterly Journal of Economics, 107(2), 407-437.

Matsuyama, K. (1992): “Agricultural productivity, comparative advantage, and economic growth,” Journal of Economic Theory, 58, 317-334.

Mehlum, H., K. Moene, and R. Torvik (2006): “Institutions and the resource curse,” The Economic Journal, 116, 1-20.

Papyrakis, E., and R. Gerlagh (2004): “The resource curses hypothesis and its transmission channels," Journal of Comparative Economics, 32, 181-193.

(2007): "Resource abundance and economic growth in the United States," European Economic Review, 51(4), 1011-1039. 
Rosenstein-Rodan, P. N. (1943): "Problems of industrialisation of Eastern and South-Eastern Europe," The Economic Journal, 53, 202-211.

Ruppert, D., S. Sheather, and M. Wand (1995): “An effective bandwidth selector for local least squares regression," Journal of the American Statistical Association, 90(432), 1257-1270.

SAchs, J. D., AND A. M. WARnER (1995. revised 1997, 1999): "Natural resource abundance and economic growth," National Bureau of Economic Research Working Paper No. 5398, Cambridge, MA.

(1997): "Sources of slow growth in African economies," Journal of African Economies, $6,335-376$.

(1999a): "The big push, natural resources booms and growth," Journal of Development Economics, 59, 43-76.

(1999b): "Why do rsource-abundant economies grow more slowly," Journal of Economic Growth, 4, 277-303.

- (2001): “The curse of natural resources," European Economic Review, 45, 827-838.

StIJNs, J.-P. C. (2005): "Natural resource abundance and economic growth revisited," Resources Policy, 30, 107-130.

ToRvik, R. (2002): "Natural resources, rent seeking and welfare," Journal of Development Economics, 67, 455-470.

World BANK (2006): “Governance, Investment Climate, and Harmonious Society: Compatitiveness Enhancements for 120 Cities in China," Report No. 37759-CN. 
Wu, Q., J. Cheng, and H. Wang (2005): "Change of energy consumption with the process of industrialization in China," China Industrial Economy (Zhongguo Gongye Jingji), 205(4), 3037.

Zhang, X., L. XING, S. FAN, AND X. Luo (2008): "Resource abundance and regional development in China," Economics of Transition, 16, 7-29. 
Table 1: Linear regression results for resource curse

\begin{tabular}{c|rrrrrr}
\hline & M1 & M2 & M3 & M4 & M5 & M6 \\
\hline Const & 0.763 & 0.761 & 0.766 & 0.940 & 1.182 & 1.433 \\
& $(0.031)$ & $(0.0312)$ & $(0.030)$ & $(0.552)$ & $(0.576)$ & $(0.577)$ \\
Mine & 0.856 & 0.881 & 0.811 & 1.029 & 1.145 & $1.859^{*}$ \\
& $(0.651)$ & $(0.636)$ & $(0.606)$ & $(0.760)$ & $(0.744)$ & $(0.727)$ \\
D_landlock & & 0.008 & & & -1.608 & -2.046 \\
& & $(0.102)$ & & & $(1.585)$ & $(1.552)$ \\
D_special & & & -0.010 & & -0.022 & -0.061 \\
& & & $(0.087)$ & & $(0.091)$ & $(0.093)$ \\
X_inter & & & & 0.003 & 0.192 & 0.251 \\
& & & & $(0.013)$ & $(0.181)$ & $(0.178)$ \\
log(Y_90) & & & & -0.022 & -0.052 & -0.090 \\
& & & & $(0.069)$ & $(0.0713)$ & $(0.071)$ \\
UU & & & & & & $0.008 *$ \\
& & & & & & $(0.002)$ \\
\hline$R^{2}$ & 0.0037 & 0.0039 & 0.0040 & 0.0057 & 0.0233 & 0.1116 \\
\hline
\end{tabular}

Notes: White's robust standard error in parentheses. * represents that corresponding estimates are significant at 5\% significance level. 
Table 2: Functional coefficient estimates: Manufacture case

\begin{tabular}{|c|c|c|c|c|c|}
\hline City & Constant & & _1990 & Mining & \\
\hline Beijing & .43477 (0.33 & 0.02484 & $(0.04545)$ & $2.83310(1.17649)$ & $0.00900(0.00953)$ \\
\hline Tianjing & $.08540(0.3$ & .10762 & & $2.24309(1.11031)$ & $.00639(0.00908)$ \\
\hline Shijiazhuang & & & & $.09157(1.08542)$ & $0.00573(0.00890)$ \\
\hline & 604 & & & $491(1$. & $.00864(0$ \\
\hline Qinghuangdao & 21095 & 5989 & & $.59678(1$. & 00793 \\
\hline Handan & .07245 & & & 2.43640 & $.00723(0$ \\
\hline Zhangjiakou & 0.32259 & 0.12975 & 591) & 1.88895 & 0.00480 \\
\hline Changzhou & 65212 & -0.00689 & $601)$ & $04330(1$. & $.01000(0$ \\
\hline & & & & $.14563)$ & $.00597(0$ \\
\hline & & & & 3.51 & $.01 \angle 00$ \\
\hline She & & & & & $0619(0$ \\
\hline & 12( & & & 97 & 15 \\
\hline & 3210 & & & $1.58577(0$ & .00325 \\
\hline & .32402 & 0.04140 & & $2.72142(1.16726)$ & $0.00849(0$ \\
\hline & & & & 1.76285 & $0.00419(0$ \\
\hline & & & & $590(1$ & $.00901(0$ \\
\hline Char & & & & 02 & 762( \\
\hline & & & & 56 & 56 \\
\hline & & & & $29(0$ & 260 \\
\hline & & & & 911 & $.01346(0$ \\
\hline & & & & 18) & $0.00397(0$ \\
\hline & & & & & 0777 ( \\
\hline & & & & 1.9 & $499(0$ \\
\hline & & & & & 91 \\
\hline hou & & & & 75) & 581 \\
\hline & & & & $08(1$ & 573 \\
\hline & & & & $47(1$ & $407(C$ \\
\hline & & & & $0)$ & 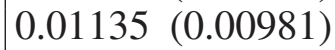 \\
\hline & & & & & $i^{\circ}$ \\
\hline & & & & 5 & $92(1)-4$ \\
\hline & & & & 39 & 84 \\
\hline & & & & 57( & $600(0$ \\
\hline & 109 & & & 2.61152 & $800(0$ \\
\hline & & & & 3.72019 & $042(0$ \\
\hline & & & & 2.7 & 0 \\
\hline & & & & & \\
\hline & & & & & 5510 \\
\hline & & & & 63 & $88(0$ \\
\hline & 551 & & & 2.19119 & $0617(0$ \\
\hline & & & & $1.20191(0$. & $0.00082(0$ \\
\hline & & & & 1.82199 & 0.00448 \\
\hline & & & & & \\
\hline & & & & & \\
\hline Jiujiang & $0.30122(0.34454)$ & 0.04494 & $(0.04486)$ & $2.69741(1.16510)$ & $0.00838(0.00946)$ \\
\hline
\end{tabular}




\begin{tabular}{|c|c|c|c|c|c|c|c|c|}
\hline Jinan & 20978 & $(0.34369)$ & .06009 & & & $(1.15605)$ & & \\
\hline Qingdao & .38949 & $(0.32619)$ & 13116 & & & $(1.00500)$ & 0.00400 & \\
\hline Zibo & 998 & $(0.33569)$ & 3435 & & 2.76900 & & 0.00870 & \\
\hline Yantai & 729 & 4348) & 04721 & & & $1.16369)$ & & \\
\hline Weifang & 0.18111 & $(0.34339)$ & .06493 & $(0.04440)$ & & $(1.15263)$ & .00779 & \\
\hline Jining & 1.12762 & $(0.33579)$ & .07204 & $(0.04716)$ & 3.45840 & $(1.20306)$ & .01240 & \\
\hline Taian & 1.69592 & $(0.33972)$ & .10094 & $(0.05313)$ & 3.64776 & (1.12268) & .01964 & $(0.01073)$ \\
\hline Weihai & -0.32449 & $(0.31654)$ & 11004 & & 1.44484 & (0.90599) & 0.00238 & \\
\hline Linyi & 1692 & 3572) & .12677 & & & & & \\
\hline Zhengzhou & & & & & & & & \\
\hline Luoyang & -0.04107 & 034) & & & & 1849) & & \\
\hline Nanyang & 778 & 631) & & & & 3670) & & \\
\hline Wuhan & 0.69091 & 687) & & & & (1.19222) & & \\
\hline Yichang & 1.01177 & & & & 3.35706 & $(1.20162)$ & & \\
\hline Xiangfan & 0.27504 & & & & & & & \\
\hline Jingmen & & & & & & & & \\
\hline Char & & & & & & & & \\
\hline Zhuzhou & -0.34310 & & & & & & & \\
\hline Hengyang & & & & & & 9009) & & \\
\hline & & & & & & 9274) & & \\
\hline & & & & & & & & \\
\hline Chenzhou & 322 & & & & & 22) & & \\
\hline chou & & & & & & & & \\
\hline Sher & & & & & & & & \\
\hline & & & & & & & & \\
\hline & & & & & & 9814) & & \\
\hline & & & & & & & & \\
\hline Maol & & & & & & & & \\
\hline $\mathrm{Hu}$ & & & & & & & & \\
\hline Don & & & & & & & & \\
\hline ing & 1.3 & $(0$. & & & & 9842) & & \\
\hline & & & & & & 2617) & & \\
\hline & & & & & & 9786) & & \\
\hline & & & & & & & & \\
\hline Chor & & & & & & & & \\
\hline & & & & & & & & \\
\hline Deyang & & & & & 5600 & 9935) & & \\
\hline Mianyang & 181 & & & & 2878 & 8518) & & \\
\hline Leshan & & & & & & 5603) & & \\
\hline & & & & & & & & \\
\hline Zhunyi & & & & & & & & \\
\hline Kunming & & & & & 3.251 & & & \\
\hline Qujing & 1.43899 & & -0.0 & & 3.42720 & & & \\
\hline Xian & 0.24102 & & & & 2.63052 & (1.15875) & & \\
\hline Xianyang & 0.40727 & & & & 2.80594 & (1.17437) & & \\
\hline & & & & & 2.56486 & (1.15284) & & \\
\hline & & & & & 3.6900 & & & \\
\hline Xining & 1.57073 & $(0.33605)$ & -0.123 & $(0.05038)$ & 3.74822 & (1.17888) & 0.01586 & $(0.01015)$ \\
\hline
\end{tabular}

Notes: Estimated standard errors are parentheses. 
Figure 1: Resource abundance of cities in China

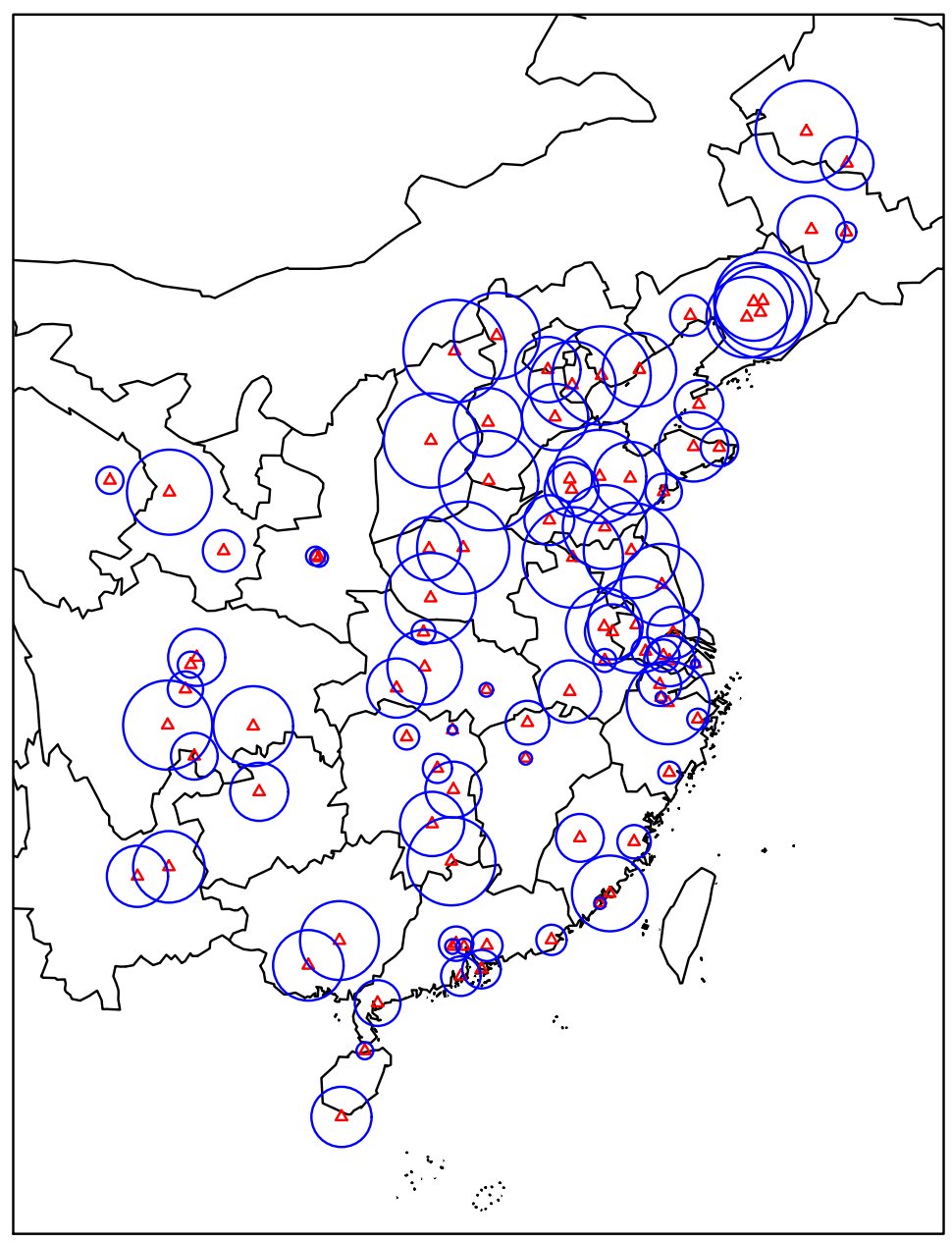

Notes: $\triangle$ represents the location of a city. The scale of resource abundance is expressed by the size of circles (length of radius of circles). 
Figure 2: Estimation results : $z=$ manufacture
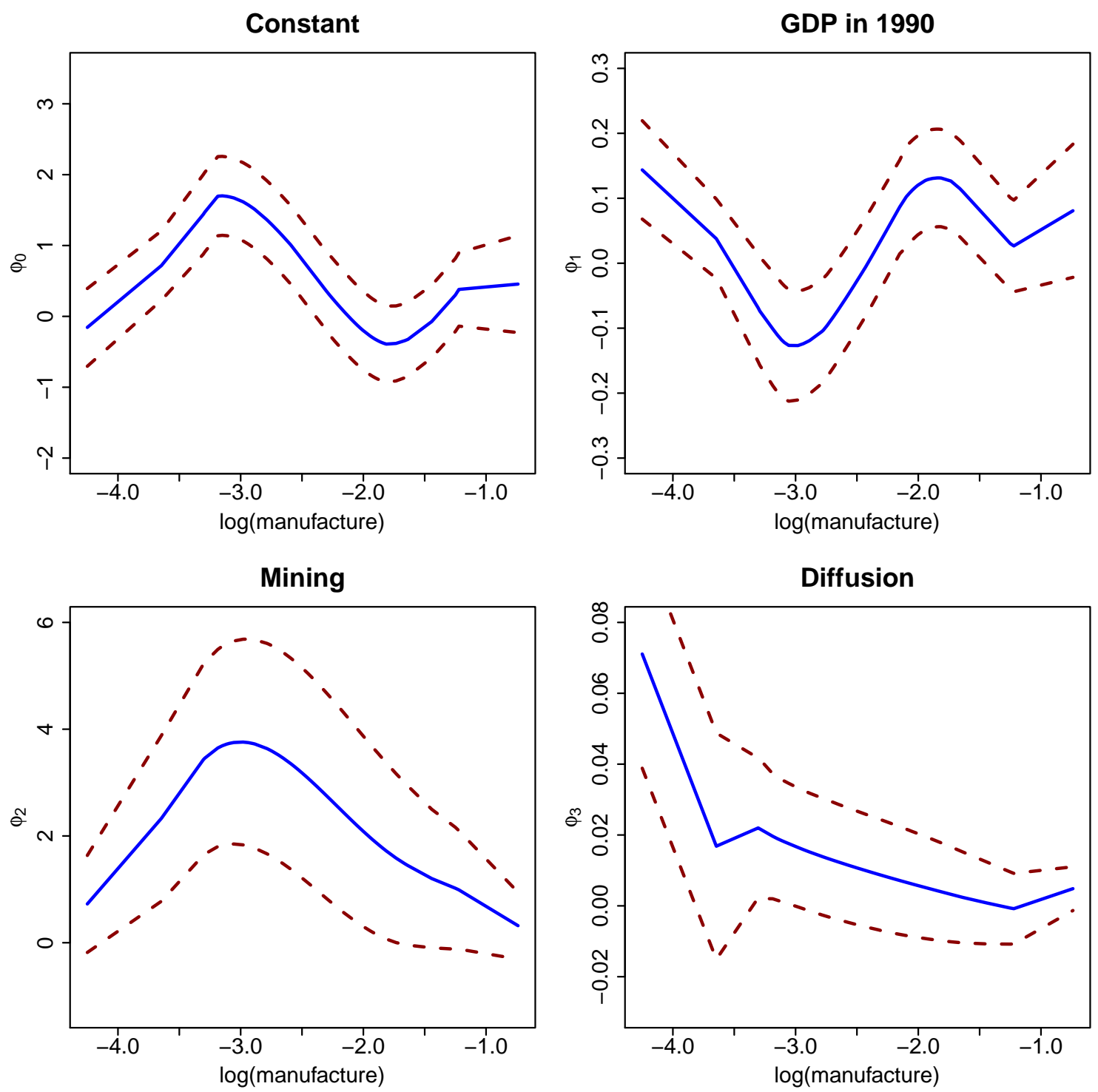

Notes: Solid and dotted lines represent estimated functional coefficients and 95\% confidence bands, respectively. 
Figure 3: Estimation results : $z=\mathrm{R} \& \mathrm{D}$
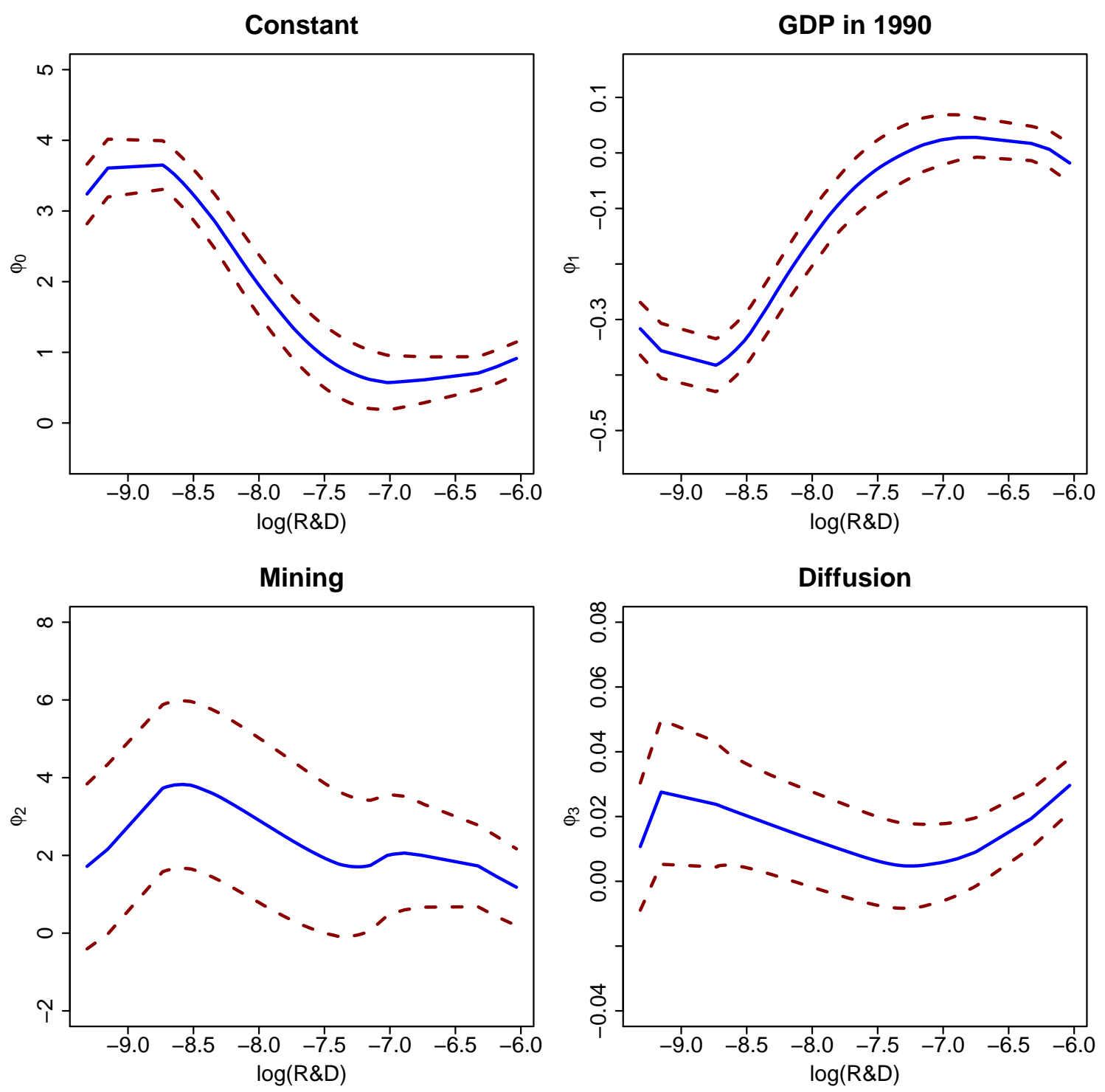

Notes: Solid and dotted lines represent estimated functional coefficients and 95\% confidence bands, respectively. 
Figure 4: Estimation results : $z=$ teacher
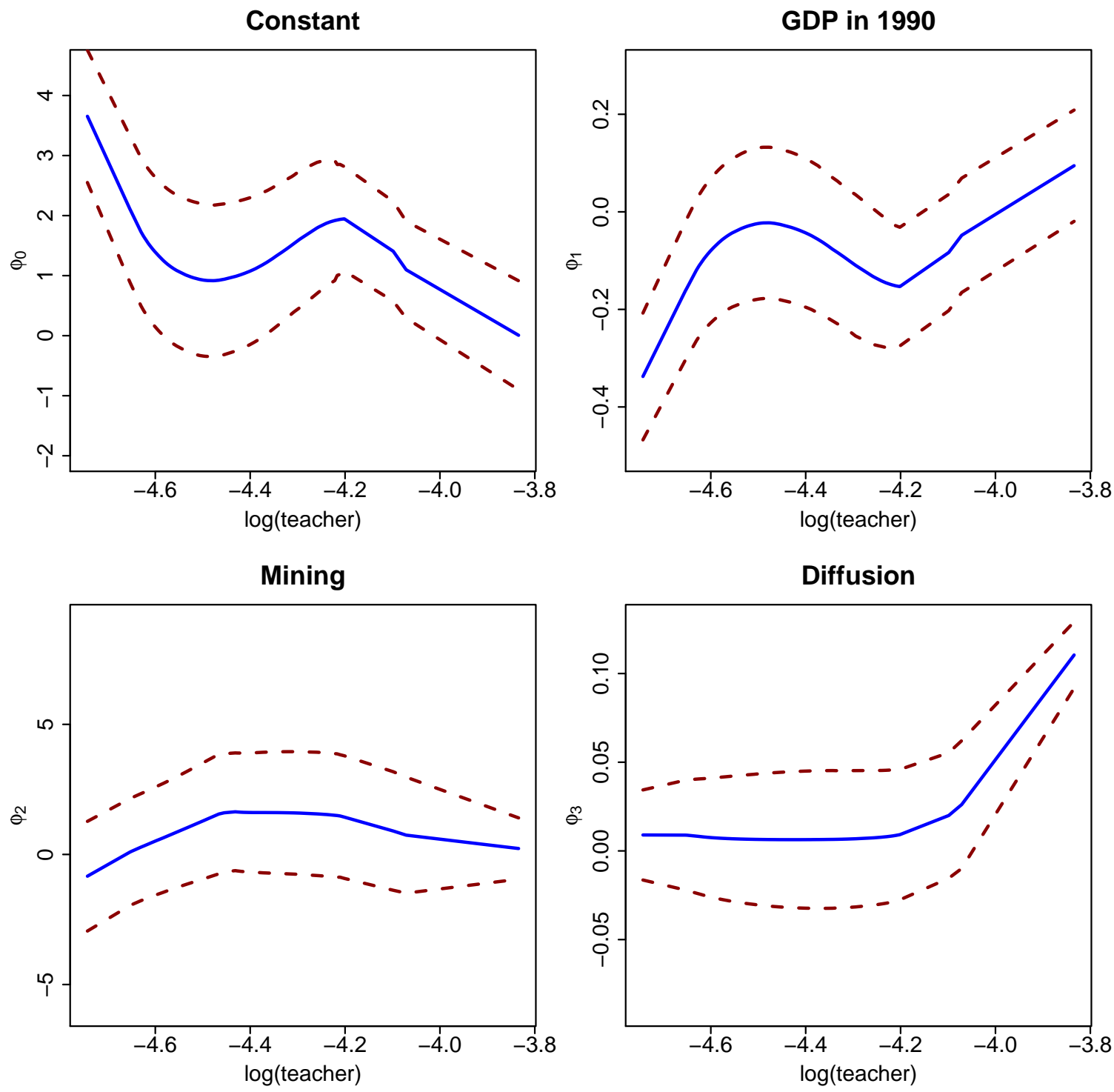

Notes: Solid and dotted lines represent estimated functional coefficients and 95\% confidence bands, respectively. 
Figure 5: Estimation results : $z=$ court
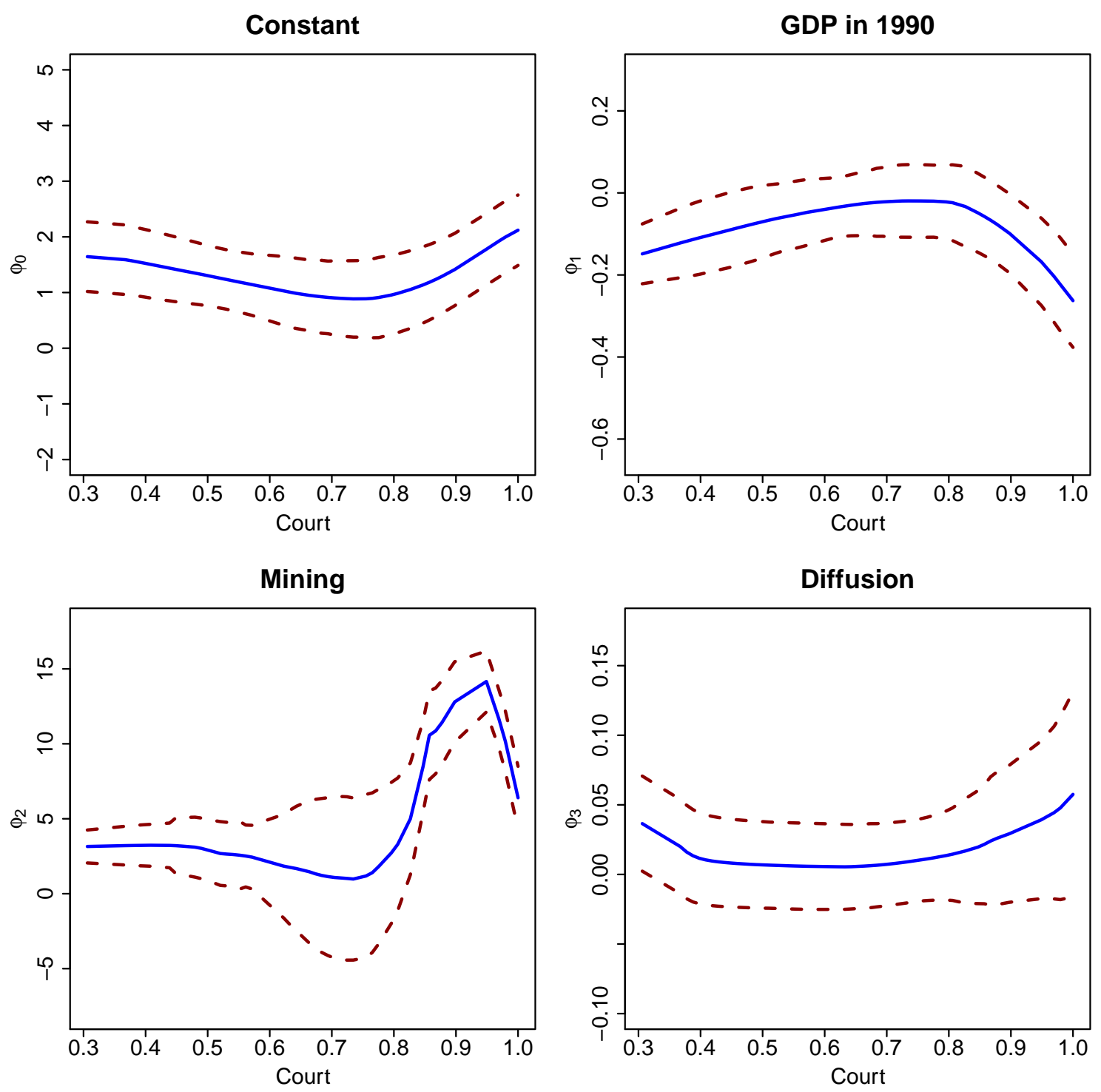

Notes: Solid and dotted lines represent estimated functional coefficients and 95\% confidence bands, respectively. 
Figure 6: Estimation results $: z=$ FDI
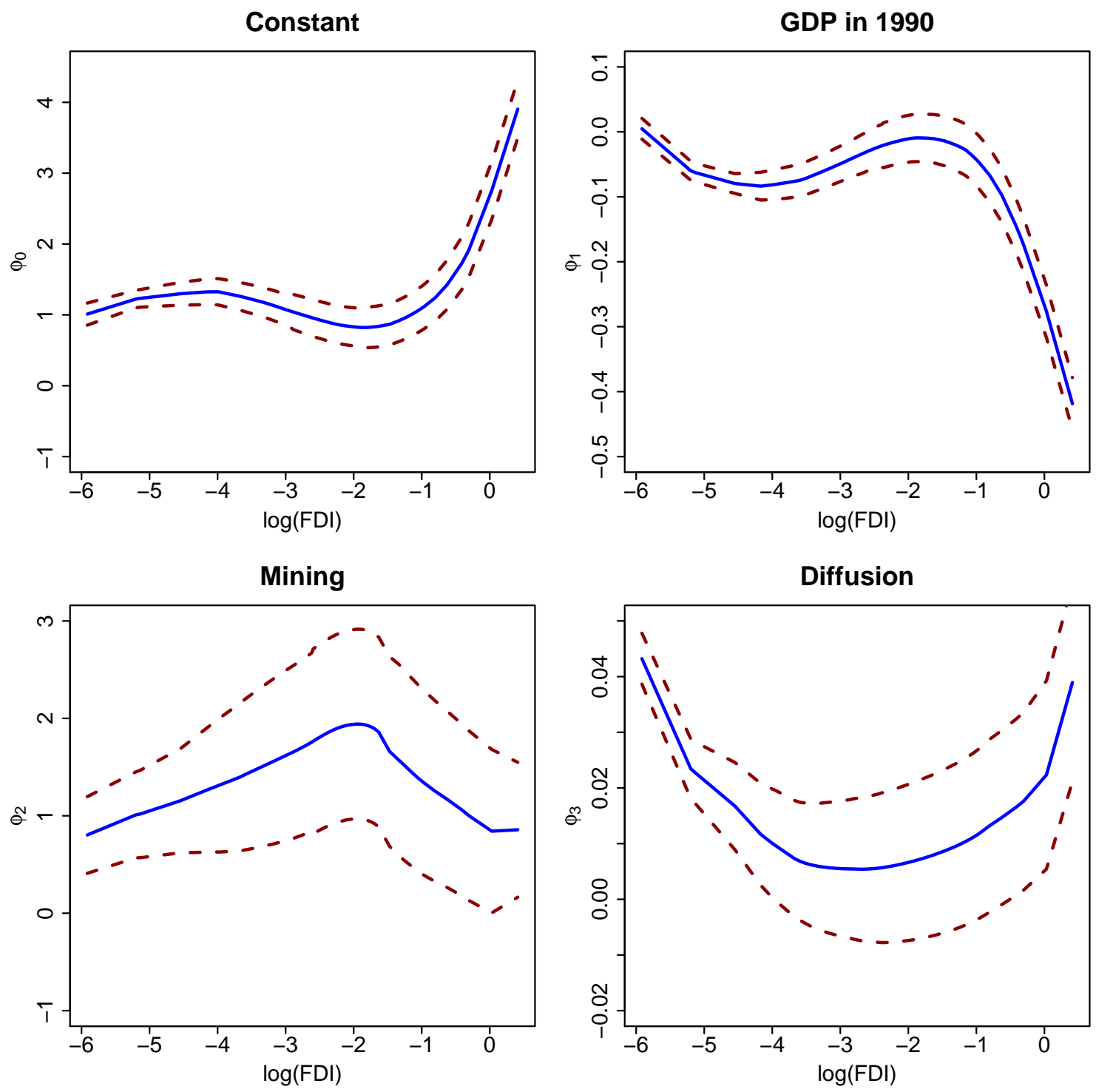

Notes: Solid and dotted lines represent estimated functional coefficients and 95\% confidence bands, respectively. 
APPENDIX: Additional Results [The following Tables are not included in the paper]

Table A.1. Functional coefficient estimates: R\&D case

\begin{tabular}{|c|c|c|c|c|c|}
\hline City & Constant & GDP & 1990 & Mining & Diffusion \\
\hline Beijing & $79370(0.14309)$ & 0.00647 & $(0.02043)$ & $1.46282(0.62838)$ & $0.02417(0.00526)$ \\
\hline Tianjing & $57386(0.2$ & 0.02444 & & $.02226(0.92992)$ & $0.00600(0.00719)$ \\
\hline Shijiazhuang & $58583(0.26473)$ & -0.10579 & $(0.03019)$ & $2.58333(1.26544)$ & $0.01075(0.00880)$ \\
\hline & 68839 (0.23897) & -0.25183 & $(0.02907)$ & $.46220(1.30621)$ & $0.01690(0.00925)$ \\
\hline Qinghuangdao & $62907(0.2$ & -0.38025 & & 3.74925 (1.30697) & $0.02353(0.01141)$ \\
\hline Handan & $96588(0.2$ & & & $2.91634(1.28722)$ & $01298(0$ \\
\hline Zhangjiakou & $.29049(0$. & 7038 & & $2.30869)(1.23$ & $00889(0$ \\
\hline Changzhou & $0.60989)(0.1$ & & & $1.99265(0.80487)$ & $0.00925(0.00639)$ \\
\hline Taiyuan & $1.14074(0.26835)$ & -0.05246 & & $.15443(1.21461)$ & $0.00779(0.00850)$ \\
\hline Datong & $39982(0.2$ & -0.08348 & $(0.03057)$ & $2.41355(1.25010)$ & $0.00961 \quad(0.00870)$ \\
\hline Shenyang & $0.79940(0.26484)$ & & & $1.77544(1.13285)$ & $0.00525(0.00814)$ \\
\hline Dal & 4988 & -0.1 & & 2.73060 & 0.01173 \\
\hline & $7093(0$ & & & 1.70568 & $474(C$ \\
\hline & $469(0$ & & & $3761(1$ & 0564 \\
\hline & $41564(0.2$ & 3535 & & 2.42800 & $0.00970(0$ \\
\hline Jinzhou & $58796(0.2$ & 0.02763 & & $2.06011(0.88774)$ & 0.00701 \\
\hline Chang & 7372 (0? & & & & $0.02053(0$ \\
\hline & $11(0$ & -0.0 & & $2.12634(1$ & 0.00760 \\
\hline $\mathrm{Ha}$ & $7(0$ & & & $62(1$ & 80 \\
\hline & $32(0$ & & & $80(1$ & 80 \\
\hline hai & $516(0$. & & & $1.72892(0.6$ & 0.01940 \\
\hline & $5215(0$. & & & 1.70897 & $0.00476(0$ \\
\hline & 0078 (0) & & & $581(13$ & 0.0 \\
\hline & & & & & $567(0$ \\
\hline Cha & $309(0$ & & & $48(1$ & 58 \\
\hline & $51(0$ & & & $85(1$ & $13(0$ \\
\hline & $962(0$ & & & 71 & $771 \quad(0$ \\
\hline gang & 0289 (0. & & & $20(1$. & $528(0$ \\
\hline & $6462(0$ & -0 . & & $1.84877(1$. & $0.00571(0$. \\
\hline & & & & $3.76942(1.2$ & $0.02325(0$ \\
\hline & 4 & & & & $392(0$ \\
\hline & $0(0$ & & & $97(1$ & $40(0$ \\
\hline & $434(0$ & 0.0 & & $272(1$. & $0.00495(0$ \\
\hline & $6902(0$ & -0.3 & & 3.80567 (1. & $0.02049(0$ \\
\hline & 0.80808 & -0.01330 & & 1.78497 & $0.00531(0$ \\
\hline & 01005 & & & 1.79707 (1.1 & 0.00539 \\
\hline & & & & & $0.01004(0$. \\
\hline & 0.5 & & & $2.00006(0.9$ & $0.00574(0$. \\
\hline & $2911(0$. & -0.07 & & $2.34717(1.2$ & 0.00915 \\
\hline & $0.88692(0.2$ & & & 1.87389 (1.1 & $0.00587(0.00826)$ \\
\hline Sanming & $0.57366(0.23148)$ & 0.02440 & & $2.02117(0.93054)$ & $0.00599(0.00719)$ \\
\hline & $0.63713(0.2$ & & & $1.71596(1.04124)$ & $0.00480(0.00782)$ \\
\hline & & & & $3.49726(1.30738)$ & $0.01718(0.00928)$ \\
\hline Jiujiang & $1.23302(0.26746)$ & -0.06337 & $(0.03129)$ & $2.25031(1.22999)$ & $0.00848(0.00860)$ \\
\hline
\end{tabular}




\begin{tabular}{|c|c|c|c|c|c|c|}
\hline Jinan & $77620(0.26503)$ & & & 5683 (1.12? & & \\
\hline Qingdao & $0.88580(0.26671)$ & -0.02241 & $(0.03144)$ & 1.87263 (1.15679) & 0.00587 & $(0.00826)$ \\
\hline Zibo & $0.91156(0.26705)$ & -0.02541 & $(0.03149)$ & $1.90180(1.16426)$ & .00606 & $(0.00830)$ \\
\hline Yantai & $0.60741 \quad(0.20085)$ & 0.02804 & $(0.02210)$ & $2.00545(0.81840)$ & .00887 & $(0.00646)$ \\
\hline Weifang & $0.61663(0.25027)$ & 0.01418 & $(0.02942)$ & $1.73815(1.02231)$ & 0.00493 & $(0.00771)$ \\
\hline Jining & 0.91359 (0.14099) & -0.01820 & $(0.02132)$ & $1.18125(0.60059)$ & 0.02961 & $(0.00505)$ \\
\hline Taian & $61305(0.24943)$ & 0.01495 & $(0.02934)$ & 1.74541 (1.01759) & 0.00497 & $(0.00768)$ \\
\hline Weihai & $782(0$. & 0.01391 & $(0.02945)$ & 73587 (1.02392) & 0.00491 & 0772) \\
\hline Linyi & $1564(0$. & 0.00917 & (0.02990) & $1.71176(1.04737)$ & .00477 & 786) \\
\hline Zhengzhou & $.63821(0$. & 0.01034 & $(0.02980)$ & $1.71534(1.04214)$ & 0.00479 & $0783)$ \\
\hline Luoyang & 0.82560 & -0.01540 & 3124) & $1.80464(1.13842)$ & 0.00543 & $00818)$ \\
\hline Nanyang & $0.97778(0$. & -0.03329 & 3152) & $1.97738(1.18275)$ & 0.00657 & $(0.00835)$ \\
\hline Wuhan & $1.44191(0.26713)$ & -0.08845 & $(0.03048)$ & $2.45201 \quad(1.25424)$ & 0.00987 & \\
\hline Yichang & $823(0$. & -0.091 & 44) & 2.47606 (1. & 0.01003 & 73) \\
\hline Xiangfan & $388(0$ & & & $37(1$ & & \\
\hline Jingmen & $0716(0$ & -0.3 & 96) & 2.16402 & & 55) \\
\hline Changsha & 1.35573 & -0.07839 & 3084) & 2.37280 & 0.00933 & $(0$. \\
\hline Zhuzhou & $1.85649(0.26084)$ & -0.14102 & 3053) & $2.82374(1.2$ & 0.01235 & $(0$. \\
\hline Hengyang & 26447) & -0.1 & 15) & 2.59579 & & \\
\hline & $40(0$. & & & $59(1$ & & \\
\hline Changde & $64(0$. & & & $98(1$ & & \\
\hline Chenzhou & & & & $71(0$ & & \\
\hline Guangzhou & 0.64579 & & 90) & $170(1$ & & \\
\hline Shenzhen & & -0.0 & & 212) & & \\
\hline Zhuhai & & -0.0 & 44) & $7522(1$ & 0.00588 & $(0$. \\
\hline Shantou & & 0 ? & & 87527 (1. & & \\
\hline Fosh & & & & $640(1$ & & \\
\hline Maomin & & & 77) & & & \\
\hline Huizhou & $04(0$. & -0.1 & 073) & 2101 & 0.01167 & $(0$. \\
\hline Dongguan & 0.75707 (0. & & 92) & 1499) & 0.0 & $(0$. \\
\hline Nanning & 1.74999 & -0.12 & $(0.03070)$ & $2.73070(1.27712)$ & 0.01173 & (0. \\
\hline Liuzhou & 1.65106 & -0.113 & $(0.03001)$ & $2.64248(1.27041)$ & & \\
\hline Haikou & & & & 3.75744 & & (0. \\
\hline Sanya & & & & & & \\
\hline Chongqing & 0.7 & 0.00058 & 3052) & 08509) & 0.00475 & $(0.0$ \\
\hline Chendu & 9091 (0. & -0.26635 & 896) & $2858(1.3$ & 0.01 & $(0.009$ \\
\hline Deyang & $6731 \quad(0.26787)$ & -0.043 & $(0.03157)$ & 2.07615 (1.20157) & 0.00724 & $(0.008$ \\
\hline Mianyang & $1.19675(0.26799)$ & -0.0590 & $(0.03137)$ & $2.21321 \quad(1.22477)$ & 0.00822 & $(0.008$ \\
\hline Leshan & & & $(0.03061)$ & $2.77584(1.28025)$ & & \\
\hline Yibin & 14 (U. & & & 1.92334 (1.1 & 0.00 & \\
\hline Zhunyi & $2.43959(0.24759)$ & -0.21735 & (0.02929) & $3.28357(1.30258)$ & 0.01556 & $(0.00913)$ \\
\hline Kunming & $1.38569(0.26791)$ & -0.08187 & $(0.03078)$ & $2.40065(1.24867)$ & 0.00952 & (0.00869) \\
\hline Qujing & $3.65009(0.20936)$ & -0.38233 & $(0.02894)$ & $3.72694(1.30642)$ & 0.02378 & $(0.01176)$ \\
\hline Xian & $3.51746(0.2081$ & -0.368 & $(0.02882)$ & 3.81252 (1.30795) & 0.02239 & \\
\hline Xianyang & $3.24069(0.25634)$ & -0.31660 & $(0.02885)$ & $1.71752(1.29038)$ & 0.01073 & (0.011 \\
\hline Lanzhou & $1.52115(0.26587)$ & -0.0978 & & 2.52437 (1.26147) & 0.01036 & $(0.0$ \\
\hline Tianshui & $1.86343(0.26069)$ & -0.1419 & 52) & $2.82971 \quad(1.28373)$ & 0.012 & $(0.00$ \\
\hline Xining & $2.76917(0.23605)$ & -0.26328 & $(0.02900)$ & $3.51531 \quad(1.30880)$ & 0.01734 & $(0.00929)$ \\
\hline
\end{tabular}

Notes: Estimated standard errors are in parentheses. 
Table A.2. Functional coefficient estimates: Teacher case

\begin{tabular}{|c|c|c|c|c|}
\hline City & Constant & GDP_1990 & Mining & Diffusion \\
\hline Beijing & $1.17760(0.73308)$ & 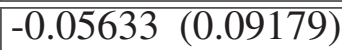 & $1.61057(1.40772)$ & $0.00639(0.02358)$ \\
\hline Tianjing & $1.09483(0.74075)$ & $-0.04566(0.09235)$ & $1.61190(1.39522)$ & $0.00635(0.02352)$ \\
\hline Shijiazhuang & $0.98779(0.75587)$ & $-0.03182(0.09351)$ & $1.63882(1.37581)$ & $0.00633(0.02329)$ \\
\hline Tangshan & $1.06971(0.74424)$ & $-0.04242(0.09264)$ & $(1.39136)$ & $0.00635(0.02348)$ \\
\hline Qinghuangdao & $1.39130(0.70692)$ & $-0.08341(0.08893)$ & $(1.42413)$ & $0.00653(0.02351)$ \\
\hline Handan & $1.53453(0.69254)$ & $-0.10068(0.08761)$ & $(1.43065)$ & $0.00671(0.02343)$ \\
\hline Zhangjiakou & $0.92365(0.76672)$ & $-0.02358(0.09418)$ & $(1.39755)$ & $0.00637(0.02294)$ \\
\hline Changzhou & $1.92701(0.56120)$ & $-0.15012(0.07760)$ & $(1.44092)$ & $0.00845(0.02259)$ \\
\hline Taiyuan & $1.87322(0.64071)$ & $-0.14217(0.08150)$ & $(1.44182)$ & $0.00776(0.02286)$ \\
\hline Datong & $1.40616(0.50468)$ & $-0.08335(0.07246)$ & $(1.38486)$ & $0.01996(0.02151)$ \\
\hline Shenyang & $0.92715(0.76990)$ & $-0.02385(0.09430)$ & $(1.35716)$ & $0.00647(0.02246)$ \\
\hline Dalian & $0.92021(0.76896)$ & $-0.02299(0.09430)$ & $(1.36561)$ & $0.00644(0.02257)$ \\
\hline Anshan & $1.20988(0.76126)$ & $-0.05816(0.09127)$ & $(1.27627)$ & $0.00712(0.02096)$ \\
\hline Fushun & $1.22334(0.76109)$ & $-0.05975(0.09118)$ & $(1.27504)$ & $0.00714(0.02091)$ \\
\hline Benxi & $0.92445(0.76960)$ & $-0.02351(0.09430)$ & $(1.36002)$ & $0.00646(0.02250)$ \\
\hline Jinzhou & $0.97869(0.76938)$ & $-0.03026(0.09373)$ & $(1.32654)$ & $0.00660(0.02203)$ \\
\hline Changchun & $0.98872(0.75573)$ & $-0.03194(0.09350)$ & (1.37602) & $0.00633(0.02330)$ \\
\hline Jilin & $0.91589(0.76597)$ & $-0.02253(0.09420)$ & (1.38331) & $0.00640(0.02279)$ \\
\hline Haerbin & $1.20716(0.72686)$ & $-0.06013(0.09114)$ & $(1.41062)$ & $0.00641 \quad(0.02359)$ \\
\hline Daqing & $1.09768(0.49038)$ & $-0.04809(0.07127)$ & $(1.35517)$ & $0.02612(0.02191)$ \\
\hline Shanghai & $0.96401(0.76987)$ & $-0.02845(0.09392)$ & $(1.33323)$ & $0.00657(0.02213)$ \\
\hline Nanjing & $0.93953(0.77049)$ & $-0.02540(0.09423)$ & (1.34719) & $0.00651(0.02232)$ \\
\hline Wuxi & $1.01393(0.75210)$ & $-0.03520(0.09325)$ & (1.38132) & $0.00633(0.02337)$ \\
\hline Xuzhou & $1.03850(0.74862)$ & $-0.03838(0.09299)$ & 1.61730 & $0.00634(0.02343)$ \\
\hline Changzhou & $1.36447(0.75860)$ & $-0.07619(0.09020)$ & $(1.26465)$ & $0.00745(0.02047)$ \\
\hline Shuzhou & $0.91779(0.76836)$ & $-0.02270(0.09429)$ & (1.37015) & $0.00643(0.02262)$ \\
\hline Nantong & $1.45447(0.75589)$ & $-0.08696(0.08950)$ & $(1.25900)$ & $0.00766(0.02020)$ \\
\hline Lianyungang & $1.91780(0.60838)$ & $-0.14859(0.07847)$ & $(1.44120)$ & $0.00826(0.02268)$ \\
\hline Yancheng & $1.40284(0.75734)$ & $-0.08078(0.08988)$ & $(1.26212)$ & $0.00754(0.02035)$ \\
\hline Yangzhou & $1.19455(0.76152)$ & $-0.05635(0.09138)$ & (1.27783) & $0.00708(0.02101)$ \\
\hline Hangzhou & $1.25498(0.76062)$ & $-0.06346(0.09096)$ & $(1.27244)$ & $0.00721(0.02080)$ \\
\hline Ningbo & $1.08577(0.76438)$ & $-0.04329(0.09233)$ & $(1.29413)$ & $0.00685(0.02145)$ \\
\hline Wenzhou & $0.98663(0.75604)$ & $-0.03167(0.09352)$ & $1.63980(1.37556)$ & $0.00633(0.02329)$ \\
\hline Huzhou & $3.65412(0.67076)$ & $-0.33755(0.07902)$ & $-0.83607(1.28120)$ & $0.00898(0.01544)$ \\
\hline Shaoxing & $2.11216(0.74038)$ & $-0.16216(0.08623)$ & $0.08806(1.24995)$ & $0.00889(0.01883)$ \\
\hline Wuhu & $1.11521(0.76343)$ & $-0.04685(0.09204)$ & $0.80875(1.28860)$ & $0.00691(0.02132)$ \\
\hline Anqing & $1.08610(0.76437)$ & $-0.04333(0.09233)$ & $0.85546(1.29406)$ & $0.00685(0.02145)$ \\
\hline Chuzhou & $0.91833(0.76851)$ & $-0.02277(0.09429)$ & $1.36369(1.36898)$ & $0.00643(0.02261)$ \\
\hline Fuzhou & $1.22256(0.72472)$ & $-0.06211(0.09093)$ & $1.61021 \quad(1.41206)$ & $0.00642(0.02360)$ \\
\hline Xiamen & $1.89587(0.62355)$ & $-0.14536(0.08061)$ & $1.52163(1.44229)$ & $0.00796(0.02279)$ \\
\hline Sanming & $1.93694(0.55680)$ & $-0.15164(0.07499)$ & $1.47914(1.43070)$ & $0.00870(0.02248)$ \\
\hline Quanzhou & $1.89875(0.62210)$ & $-0.14577(0.08045)$ & $1.51976(1.44205)$ & $0.00799(0.02277)$ \\
\hline Nanchang & $1.00590(0.76823)$ & $-0.03358(0.09336)$ & 1.01804 (1.31605) & $0.00666(0.02187)$ \\
\hline Jiujiang & $1.79294(0.66384)$ & $-0.13183(0.08478)$ & $1.55909(1.44091)$ & $0.00733(0.02310)$ \\
\hline
\end{tabular}




\begin{tabular}{|c|c|c|c|c|}
\hline & $4033(0.76335)$ & $\mid-0.02570(0.09398)$ & 1.60191 (1.37997) & 0.00635 (0.02307) \\
\hline Qingdao & $2255(0.76937)$ & $-0.02328(0.09430)$ & $1.32034(1.36230)$ & $0.00645(0.02253)$ \\
\hline Zibo & $1.43848(0.70237)$ & $-0.08911 \quad(0.08819)$ & $1.60342(1.42666)$ & $0.00658(0.02349)$ \\
\hline Yantai & $1.18420(0.73221)$ & $-0.05718(0.09171)$ & $1.61052(1.40838)$ & $0.00640(0.02358)$ \\
\hline Weifang & $1.12241(0.73695)$ & $-0.04922(0.09202)$ & $1.61114(1.39902)$ & $0.00637(0.02355)$ \\
\hline Jining & $1.28083(0.71821)$ & $-0.06961 \quad(0.09003)$ & $1.60937(1.41684)$ & $0.00645(0.02360)$ \\
\hline Taian & $8585(0.76917)$ & $-0.03113(0.09364)$ & $1.06910(1.32360)$ & $.00662(0.0$ \\
\hline Weihai & $592(0$. & $-0.03805(0.09302)$ & 1.61780 & $0.00634(0$ \\
\hline Linyi & (0237) & $-0.08911(0.08819)$ & $1.60342(1.42666)$ & $00658(0$ \\
\hline Zhengzhou & $1.14964(0.76261)$ & $-0.05101 \quad(0.09175)$ & $0.75956(1.28333)$ & $0.00699(0$ \\
\hline Luoyang & $1.11170(0.73842)$ & $-0.04784(0.09215)$ & 1.61137 (1.39759) & $0.00636(0$ \\
\hline Nanyang & $4032(0.76336)$ & $-0.02570(0.09398)$ & 1.60189 (1.37996) & $0.00635(0$ \\
\hline Wuhan & & $-0.05845(0.09131)$ & & $0.00640(0$ \\
\hline Yichang & $46(0$. & $4329(0$ & 1.612 & 0.006 \\
\hline Xiangfan & & & & $40(0$ \\
\hline Jingmen & $565(0$. & $-0.05994(0.1$ & 1.61036 & $41(0$ \\
\hline Changsha & $331(0.76780)$ & $-0.03449(0.0$ & 1.00029 (1.31349) & $0668(0$ \\
\hline Zhuzhou & $881(0.76363)$ & $-0.02550(0.0$ & $1.59980(1.37936)$ & $0635(0$ \\
\hline Hengyang & $67(0.71424)$ & $665(0$. & & 0649 (0 \\
\hline & $09(0$. & $3(0$ & 1.5 & \\
\hline Changde & $1(0$. & & 8( & \\
\hline Chenzhou & & & $62(1$ & \\
\hline Guangzhou & $58(0.7$ & $79(0$. & 59 (1. & \\
\hline Shenzhen & $58(0.55199)$ & & $72(0.7$ & $44(0$ \\
\hline Zhuhai & 2870) & $-0.15329(0.0$ & & $16(0$ \\
\hline Shantou & & $-0.02277)(0.0$ & & \\
\hline Fosl & & & & $42(0$ \\
\hline Mao & & & & \\
\hline Huizhou & $9(0$. & $973(0$. & $950(1$ & $84(0$ \\
\hline Dongguan & $50(0$. & & & $49(0$ \\
\hline Nanning & $77(0.76511)$ & $-0.02267(0.0$ & $1.48662(1.3$ & $39(0$ \\
\hline Liuzhou & $11(0.69472)$ & $-0.09702(0.0$ & & $0667 \quad 0$ \\
\hline & & & & \\
\hline Sanya & & & & \\
\hline Chongqing & 6180) & $-0.05469)(0$. & $1888(1$ & $05(0$ \\
\hline Chendu & 5003) & $-0.11923(0$. & 3083 (1.' & $31(0$ \\
\hline Deyang & $56(0$. & -0.05015 & 0.76921 & $597(0$. \\
\hline Mianyang & $70(0.77049)$ & $-0.02492(0.09$ & $1.24055(1.34991)$ & 0.00650 \\
\hline Leshan & & & & \\
\hline & & & $47(1.2$ & \\
\hline Zhunyi & $0.99678(0.75456)$ & $-0.03298(0.0$ & 1.63232 & $33(0$. \\
\hline Kunming & $1.65527(0.75127)$ & $-0.11051 \quad(0.08829)$ & $0.32175(1.25196)$ & $0.00816(0.01971)$ \\
\hline Qujing & $1.21310(0.72603)$ & $-0.06090(0.09106)$ & $1.61030(1.41118)$ & $0.00641 \quad(0.02359)$ \\
\hline Xian & $1555(0.75187)$ & $-0.03541 \quad(0.09323)$ & $1.62336(1.38164)$ & $0.00633(0.02338)$ \\
\hline Xianyang & $1.18388(0.73225)$ & $-0.05714(0.09171)$ & $1.61053(1.40834)$ & 40 \\
\hline Lanzhou & 1.01759 & $-0.03567(0.09$ & $1.62265(1.38204)$ & $33(0$. \\
\hline Tianshui & $92(0.69998)$ & $325(0.08$ & $1.60126(1.428$ & 0.00 \\
\hline Xining & $2.05387(0.74282)$ & $-0.15571 \quad(0.08659)$ & $0.12004(1.24925)$ & $0.00885(0.01896)$ \\
\hline
\end{tabular}

Notes: Estimated standard errors are parentheses. 
Table A.3. Functional coefficient estimates: Court case

\begin{tabular}{|c|c|c|c|c|c|}
\hline City & Constant & GDP_1990 & $\mathrm{Mi}$ & ning & Diffusion \\
\hline Beijing & $1.43799(0.35720)$ & 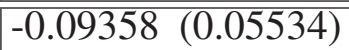 & 3.21971 & (0.90740) & $0.00857(0.01927)$ \\
\hline Tianjing & $1.02929(0.37530)$ & $-0.03457(0.04381)$ & 1.83897 & $(2.10080)$ & $0.00550(0.01861)$ \\
\hline Shijiazhuang & $0.98520(0.42900)$ & $-0.02394(0.05617)$ & 3.29039 & (2.69119) & $0.01456(0.02022)$ \\
\hline Tangshan & $1.23367(0.32472)$ & $-0.05989(0.05029)$ & 2.64357 & (1.29008) & $0.00638(0.01876)$ \\
\hline Qinghuangdao & $0.91225(0.39659)$ & $-0.02190(0.05092)$ & 1.13966 & (3.20308) & $0.00699(0.01810)$ \\
\hline Handan & $1.48306(0.36517)$ & $-0.10153(0.05473)$ & 3.22843 & $(0.86637)$ & $0.00965(0.01951)$ \\
\hline Zhangjiakou & $0.92370(0.39810)$ & $-0.02294(0.05037)$ & 1.21776 & $(3.12122)$ & $0.00659(0.01818)$ \\
\hline Changzhou & $1.34907(0.33898)$ & $-0.07776(0.05499)$ & 3.10496 & (1.21589) & $0.00728(0.01898)$ \\
\hline Taiyuan & $0.90335(0.40498)$ & $-0.02103(0.05277)$ & 1.08267 & $(3.26842)$ & $0.00746(0.01804)$ \\
\hline Datong & $1.64441(0.38036)$ & $-0.14859(0.04432)$ & 3.14981 & $(0.66766)$ & $0.03652(0.02077)$ \\
\hline Shenyang & $1.18760(0.32915)$ & $-0.05383(0.04983)$ & 2.57073 & (1.37884) & $0.00608(0.01882)$ \\
\hline Dalian & $0.95023(0.38629)$ & $-0.02583(0.04751)$ & 1.46715 & $(2.88441)$ & $0.00598(0.01836)$ \\
\hline Anshan & $0.92370(0.39810)$ & $-0.02294(0.05037)$ & 1.21776 & $(3.12122)$ & $0.00659(0.01818)$ \\
\hline Fushun & $1.50576(0.36760)$ & $(0.05441)$ & 3.23187 & $(0.84965)$ & $0.01046(0.01965)$ \\
\hline Benxi & $1.16502(0.33259)$ & $-0.05071 \quad(0.04937)$ & 2.51407 & (1.25520) & $0.00596(0.01882)$ \\
\hline Jinzhou & $0.98520(0.42900)$ & $-0.02394(0.05617)$ & 3.29039 & (2.69119) & $0.01456(0.02022)$ \\
\hline Changchun & $0.89624(0.40938)$ & -0.02031 & 1.05007 & $(3.30423)$ & $0.00796(0.01$ \\
\hline Jilin & $0.95023(0.38629)$ & $-0.02583(0.04751)$ & 1.46715 & $(2.88441)$ & $0.00598(0.01836)$ \\
\hline Haerbin & $1.27995(0.32615)$ & $-0.06656(0.05251)$ & 2.79877 & $(1.26463)$ & $0.00668(0.01882)$ \\
\hline Daqing & $1.57024(0.37548)$ & $-0.11786(0.05264)$ & 3.21453 & $(0.80491)$ & $0.01612(0.02042)$ \\
\hline Shanghai & $1.39299(0.34882)$ & $-0.08554(0.05532)$ & 3.17381 & (1.16125) & $0.00784(0.01910)$ \\
\hline Nanjing & $1.00627(0.38209)$ & $-0.03219(0.04454)$ & 1.75546 & $(2.32373)$ & $0.00546(0.01856)$ \\
\hline Wuxi & $1.32683(0.33399)$ & $-0.07395 \quad 0.0$ & 3.02469 & (1.22937) & $0.00704(0.01898)$ \\
\hline Xuzhou & $1.02929(0.37530)$ & $-0.03457(0.04381)$ & 1.83897 & $(2.10080)$ & $0.00550(0.01861)$ \\
\hline Changzhou & $0.93618(0.39284)$ & $-0.02432(0.04840)$ & 1.32775 & $(3.01966)$ & $0.00627(0.01835)$ \\
\hline Shuzhou & $1.77746(0.39018)$ & $-0.16781 \quad(0.06463)$ & 14.15797 & $(1.23690)$ & $0.03927(0.03445)$ \\
\hline Nantong & $0.89563(0.43009)$ & $-0.01987(0.05363)$ & 1.40538 & $(3.23646)$ & $0.01117(0.01820)$ \\
\hline Lianyungang & $0.89624(0.40938)$ & $-0.02031 \quad(0.05327)$ & 1.05007 & (3.30423) & $0.00796(0.01797)$ \\
\hline Yancheng & $1.18760(0.32915)$ & $-0.05383(0.1$ & 2.57073 & (1.37884) & $0.00608(0.01882)$ \\
\hline Yangzhou & $0.89624(0.40938)$ & $-0.02031 \quad(0.05327)$ & 1.05007 & $(3.30423)$ & $0.00796(0.01797)$ \\
\hline Hangzhou & $2.11983(0.38440)$ & $-0.26267(0.06921)$ & 6.39909 & (1.27519) & $0.05751(0.04480)$ \\
\hline Ningbo & $0.91096(0.43830)$ & $-0.02010(0.05342)$ & 1.81352 & $(3.13456)$ & $0.01192(0.01850)$ \\
\hline Wenzhou & $1.41546(0.35310)$ & $-0.08961 \quad(0.05558)$ & 3.20333 & (1.13557) & $0.00818(0.01917)$ \\
\hline Huzhou & $0.98492(0.38408)$ & $-0.02991 \quad(0.04537)$ & 1.67657 & $(2.52521)$ & $0.00555(0.01844)$ \\
\hline Shaoxing & $0.95557(0.43144)$ & $-0.02191 \quad(0.05473)$ & 2.72281 & $(2.86047)$ & $0.01359(0.01945)$ \\
\hline Wuhu & $1.13712(0.41687)$ & $-0.04875(0.05841)$ & 8.47350 & $(1.85136)$ & $0.01963(0.02468)$ \\
\hline Anqing & $1.05392(0.42408)$ & $-0.03321 \quad(0.05946)$ & 4.99527 & $(2.26485)$ & $0.01685(0.02281)$ \\
\hline Chuzhou & $0.95557(0.43144)$ & $-0.02191 \quad(0.05473)$ & 2.72281 & $(2.86047)$ & $0.01359(0.01945)$ \\
\hline Fuzhou & $0.91096(0.43830)$ & $-0.02010(0.05342)$ & 1.81352 & $(3.13456)$ & $0.01192(0.01850)$ \\
\hline Xiamen & $1.13712(0.41687)$ & $-0.04875(0.05841)$ & 8.47350 & (1.85136) & $0.01963(0.02468)$ \\
\hline Sanming & $0.98520(0.42900)$ & $-0.02394(0.05617)$ & 3.29039 & (2.69119) & $0.01456(0.02022)$ \\
\hline Quanzhou & $0.95557(0.43144)$ & $-0.02191 \quad(0.05473)$ & 2.72281 & $(2.86047)$ & $0.01359(0.01945)$ \\
\hline Nanchang & $0.89563(0.43009)$ & $-0.01987(0.05363)$ & 1.40538 & (3.23646) & $0.01117(0.01820)$ \\
\hline Jiujiang & $1.41299(0.39483)$ & $-0.09887(0.05854)$ & 12.79616 & (1.63123) & $0.02932(0.02998)$ \\
\hline
\end{tabular}




\begin{tabular}{|c|c|c|c|c|c|c|c|}
\hline & 4235 (0.33606) & & $(0.04880)$ & & & & \\
\hline Qingdao & $2556(0.39290)$ & -0.20335 & $(0.06790)$ & .62817 & & & \\
\hline Zibo & 093 & 07659 & $.05790)$ & 256 & $67)$ & & \\
\hline Yantai & $712(0.41687)$ & & $(0.05841)$ & & & & \\
\hline Weifang & $.89563(0.43009)$ & -0.01987 & $(0.05363)$ & 1.40538 & & & \\
\hline Jining & $.23530(0.40755)$ & -0.06661 & $(0.05798)$ & 10.86572 & $(1.73752)$ & 02401 & \\
\hline Taian & $95557(0.43144)$ & -0.02191 & $(0.05473)$ & 2.72281 & $(2.86047)$ & .01359 & 194. \\
\hline Weihai & $3712(0.41687)$ & -0.04875 & & 8.47350 & & 0.01963 & \\
\hline Linyi & & & & & & & \\
\hline Zhengzhou & 43009) & & $(0.05363)$ & & & & \\
\hline Luoyang & $32683(0$ & & $(0.05441)$ & & & & \\
\hline Nanyang & 33606) & & 4880) & 072 & 1.29040) & & \\
\hline Wuhan & $492(0.38408)$ & -0.02991 & 4537) & 1.67657 & $(2.52521)$ & 0.00555 & \\
\hline Yichang & $383(0.41202)$ & & 819) & 6982 & & & \\
\hline Xiangfan & $76(0$. & & & & & & \\
\hline Jing & & & & & & & \\
\hline Cha & 29) & & & & & & \\
\hline Zhuzhou & $71(0$ & & & & & & \\
\hline Hengyang & $1.52789(0.36954)$ & & & & & & \\
\hline & 1.00627 & & & & & & \\
\hline Chan & $6(0$. & & & & & & \\
\hline Chen & $2(0$ & & & & & & \\
\hline Gua & $9(0$ & & & & & & \\
\hline Shen & & & & & & & \\
\hline Zhuhai & $25(0$. & & & & & & \\
\hline & 309) & & & & & & \\
\hline & 2608) & & (002) & & & & \\
\hline $\mathrm{Ma}$ & & & & & & & \\
\hline Hui & & & & & & & \\
\hline Don & $89(0$ & & & & & & \\
\hline & 71( & & & & & & \\
\hline & 810) & & & & & & \\
\hline & 898) & & & & (1.21589) & & \\
\hline & $07(0$ & & & & & & \\
\hline Chor & 27( & & & & & & \\
\hline & 1( & & & & & & \\
\hline & $12(0$ & & 841) & & & & \\
\hline Mianyang & 498) & & 277) & & $(3.26842)$ & 0. & 04 \\
\hline Leshan & $0.89624(0$. & & 327) & & $(3.30423)$ & & 797 \\
\hline & & & & & (1.29040) & & \\
\hline Zhunyi & & & & & & & \\
\hline Kunming & & & & & & & \\
\hline Qujing & 0.95023 & & & & $(2.88441)$ & 0.00 & \\
\hline Xian & $1.46041(0.36146)$ & & 5505) & & $(0.88569)$ & & \\
\hline Xianyang & $1.25671(0.32576)$ & -0.06304 & $(0.05140)$ & 2.68159 & $(1.29346)$ & 0.00653 & \\
\hline Lan & $1.54946(0.37210)$ & & & & & & \\
\hline & & & & & & 0.0078 & \\
\hline Xining & $1.58971(0.37993)$ & -0.12200 & $(0.05147)$ & 3.20647 & $(0.78546)$ & 0.02003 & $(0.02058$ \\
\hline
\end{tabular}

Notes: Estimated standard errors are parentheses. 
Table A.4. Functional coefficient estimates: FDI case

\begin{tabular}{|c|c|c|c|c|}
\hline City & Constant & GDP_1990 & Mining & Diffusion \\
\hline Beijing & $0.82183(0.17392)$ & $-0.00936(0.02219)$ & $11.93290(0.59256)$ & $0.00720(0.00867)$ \\
\hline Tianjing & $.94610(0.18053)$ & $-0.02181(0.02385)$ & $1.52807(0.59419)$ & $0.00971(0.00904)$ \\
\hline Shijiazhuang & $.89468(0.16023)$ & (0.02097) & $1.85744(0.58384)$ & $0.00571(0.00820)$ \\
\hline Tangshan & $.84386(0.16268)$ & $(0.02187)$ & $1.92715(0.58933)$ & $0.00631(0.00843)$ \\
\hline Qinghuangdao & $83150(0.17552)$ & $(0.02244)$ & $1.89283(0.59257)$ & $0.00771 \quad(0.00876)$ \\
\hline Handan & $94807(0.15826)$ & -0.02886 & $1.77612(0.57677)$ & 0.00546 \\
\hline Zhangjiakou & $1.01870(0.15291)$ & $-0.04027(0.01$ & $1.68079(0.54346)$ & 0.00545 \\
\hline Changzhou & $1.25755(0.11952)$ & $-0.07581 \quad(0.01$ & $1.40465(0.46340)$ & $0.00717(0.00637)$ \\
\hline Taiyuan & $0.89873(0.16004)$ & -0.02131 & $1.85157(0.58331)$ & $0.00568(0.00818)$ \\
\hline Datong & $1.32664(0.11294)$ & -0.08166 & $1.30692(0.41267)$ & $0.01007(0.00593)$ \\
\hline Shenyang & $1.05138(0.18657)$ & -0.03590 & $1.39603(0.58314)$ & $0.01098(0.00917)$ \\
\hline Dal & $2808(0.2$ & $769(0$. & $1.16837(0$. & 0.01471 \\
\hline & $.97398(0$. & $296(0$ & 797 & 541( \\
\hline Fushun & $0.98138(0.15610)$ & $-0.03418(0$. & $1.72783(0.5$ & 0.00541 \\
\hline Benxi & $1.26232(0.11913)$ & $-0.07616(0.0$ & $1.39773(0.46086)$ & $0.00728(0.00636)$ \\
\hline Jinzhou & $0.82282(0.17418)$ & -0.00941 & $1.92898(0.59261)$ & $0.00728(0.00868)$ \\
\hline Changchun & $2193(0.16439)$ & & $1.93980(0.59230)$ & $0.00698(0.00862)$ \\
\hline Jilin & $1.07102(0.12996)$ & $-0.04863(0$. & $1.62217(0.5$ & $0.00551(0.00739)$ \\
\hline $\mathrm{Hae}$ & $95576(0.1$ & $007(0$ & $414(0$ & $0.00544(0$. \\
\hline $\mathrm{Da}$ & .23333 & $261(0$. & $352(0$ & $0.02279(0$ \\
\hline Shanghai & $0.82695(0.17496)$ & $-0.00966(0.02235)$ & $1.91230(0$. & $0.00751(0.00873)$ \\
\hline & $0.83865(0.17616)$ & $-0.01043(0.02256)$ & $1.85841 \quad(0.59$ & $0.00795(0.00880)$ \\
\hline & $1.23422(0.19829)$ & & $1.25635(0.56$ & $0.01316(0.00944)$ \\
\hline $\mathrm{Xuz}$ & $0.89285(0.16032)$ & & $1.86005(0$. & 0.00572 \\
\hline Char & $1.11808(0.19066)$ & -0.0 & $1.33600(0$ & $0.01178(0$. \\
\hline & $.75548(0.2$ & $634(0$. & $217(0$ & $2234(0$ \\
\hline Nan & $1.24230(0$. & $-0.06742(0$. & $5197(0$ & 0.01324 \\
\hline Lianyungang & $0.92980(0.15855)$ & $-0.02604)$ & $394(0.57965)$ & $0.00552(0.00803)$ \\
\hline Yancheng & $0.93636(0.15884)$ & $-0.02705(0$. & $1.79398(0.578$ & $0.00549(0.0$ \\
\hline & $0.84482(0.16261)$ & 1333 (0. & $1.92596(0.5$ & $0.00630(0.0$ \\
\hline Hal & $.87738(0.1$ & $35(0$ & $1.88139(0$ & $0.00585(0$. \\
\hline & $83708(0$. & & $659(0$ & $790(0$. \\
\hline Wenzhou & $1.17238(0.12$ & $-0.06332(0$. & 1.51563 & $0.00590(0.00690)$ \\
\hline & 0.83700 & -0.01182 & $1.93477(0.59020)$ & $0.00647(0.00848)$ \\
\hline Shaoxing & $0.90620(0.15969)$ & $-0.02243(0.01996)$ & $1.84052(0.58228)$ & $0.00563(0.00815)$ \\
\hline & $0.86334(0.16218)$ & $-0.01650(0.02128)$ & $1.90003(0.5$ & $0.00599(0.00831)$ \\
\hline & $0.94972(0.1581$ & & $1.77357(0.5$ & $0.00545(0.00795)$ \\
\hline Chuzhou & $0.85581 \quad 0.1618$ & $-0.01530(0$. & $1.91055(0$. & $0.00610(0.0$ \\
\hline & $0.91592(0.17905)$ & $-0.01873(0.02364)$ & $1.57380(0.59803)$ & $0.00932(0.00900)$ \\
\hline Xiamen & $1.24169(0.19882)$ & $-0.06732(0.02517)$ & $1.25229(0.56377)$ & $0.01323(0.00944)$ \\
\hline Sanming & $0.87461 \quad(0.16138)$ & $-0.01807(0.02115)$ & $1.88516(0.58637)$ & $0.00588(0.00826)$ \\
\hline Quanzhou & $0.92484(0.17946)$ & $-0.01964(0.02370)$ & $1.55987(0.59688)$ & $0.00944(0.00901)$ \\
\hline & $0.82140(0.17379)$ & $-0.00933(0.02217)$ & $1.93460(0.59253)$ & $0.00716(0.00866)$ \\
\hline Jiujiang & $0.92161(0.15895)$ & $-0.02479(0.01979)$ & $1.81683(0.58006)$ & $0.00555(0.00806)$ \\
\hline
\end{tabular}




\begin{tabular}{|c|c|c|c|c|}
\hline Jinan & $82950(0.16367)$ & $.01037(0.02196)$ & $94039(0.59160)$ & $0.00669(0.00854)$ \\
\hline Qingdao & 1.09454 (0.18919) & $-0.04291 \quad(0.02462)$ & $1.35616(0.57839)$ & $0.01150(0.00923)$ \\
\hline Zibo & $0.96144(0.15758)$ & $-0.03095(0.01829)$ & $1.75558(0.55665)$ & $0.00543(0.00790)$ \\
\hline Yantai & $1.01441(0.18442)$ & $-0.02996(0.02408)$ & $43790(0.58666)$ & $0.01054(0.00913)$ \\
\hline Weifang & $0.85115(0.16217)$ & $-0.01448(0.02174)$ & $1.91740(0.58938)$ & $0.00618(0.00838)$ \\
\hline Jining & $1.03964(0.15118)$ & $-0.04369(0.01696)$ & $1.65610(0.53947)$ & $0.00547(0.00753)$ \\
\hline Taian & $1.05298(0.14023)$ & $-0.04586(0.01683)$ & $1.64148(0.53607)$ & $0.00548(0.00747)$ \\
\hline Weihai & $0.96375(0.18144)$ & $-0.02364(0.02397)$ & $1.50299(0.59201)$ & $0.00993(0.00906)$ \\
\hline Linyi & $1.08677(0.12976)$ & $-0.05091 \quad(0.01649)$ & $1.60584(0.52778)$ & $0.00554(0.00733)$ \\
\hline Zhengzhou & $0.98538(0.15552)$ & $-0.03484(0.01811)$ & $1.72250(0.55101)$ & $0.00541 \quad(0.007$ \\
\hline Luoyang & $2056(0$. & $130(0$ & $1.45469(0$. & 0.00643 \\
\hline Nanyang & $1.24575(0$. & $-0.07484(0$. & $1.42175(0.46981)$ & $0.00688(0$ \\
\hline Wuhan & $0.82577 \quad(0.16399)$ & $-0.00981 \quad(0.02204)$ & 1.94138 (0.59197) & $0.00682(0$. \\
\hline Yichang & $0.94651 \quad(0.15834)$ & $-0.02861 \quad(0.01944)$ & $1.77853(0.57702)$ & $0.00546(0.007$ \\
\hline Xiangfan & $1.09121(0.12955)$ & $-0.05155(0.01646)$ & $1.60125(0.52659)$ & $0.00555(0.007$ \\
\hline Jingmen & $5712(0.16227)$ & $-0.01704(0.02123)$ & $1.89502(0.5$ & 0.00595 \\
\hline Changsha & $38(0$ & $2(0$ & $62(0$ & $83(0$ \\
\hline Zhuzhou & 0.83826 & $207(0$ & 9004) & $44(0$ \\
\hline Hengyang & $0.94260(0.1$ & $801 \quad(0.01948)$ & $1.78453(0.57765)$ & $0.00547 \quad 0$ \\
\hline Yueyang & $0.84244(0.16278)$ & $-0.01288(0.02189)$ & $1.92888(0.58951)$ & $0.00634(0$. \\
\hline Changde & $0.92682(0.15869)$ & $-0.02558(0.01973)$ & $0861 \quad(0.57928)$ & 0.00553 \\
\hline Chenzhou & & $-0.01504(0.02169)$ & $282(0$. & $0612(0$. \\
\hline Guangzhou & $650(0.1$ & $77(0.1$ & 1.66075 & $0.00866(0$ \\
\hline Shenzhen & & $45(0$. & & $02(0$ \\
\hline Zhuhai & $2565(0$. & 00 & $45(0$. & $58(0$ \\
\hline Shantou & & 280 & $79(0$. & $49(0$. \\
\hline Foshan & $974(0.19938)$ & $-0.06864(0.02519)$ & 4796 (0. & $330(0$. \\
\hline Maomin & & $-0.05197(0.01643)$ & $818(0$. & 566 \\
\hline Huizhou & & -0.41857 & $74(0$. & $395(0$. \\
\hline Dongguan & $81 \quad(0.2$ & & $8(0$ & $67(0$ \\
\hline Nanning & $31(0$. & $-0.01266(0$. & 8966) & $0.00637 \quad 0$. \\
\hline Liuzhou & $862(0$. & $586(0.0$ & $575(0$. & $552(0$. \\
\hline Haikou & $38(0$. & $80(0.02446)$ & $1.37888(0.58131)$ & $120(0.00920)$ \\
\hline Sanya & $1.85016(0.22957)$ & $-0.16413(0.02523)$ & $1.02160(0.53147)$ & $0.01726(0.009$ \\
\hline Chongqing & $0.97234(0.15660)$ & & $1.74029(0.55445)$ & $41 \quad 0.007$ \\
\hline Chendu & $1.13133(0.1291$ & $-0.05725(0.0$ & $16(0$. & $68(0$ \\
\hline Deyang & 1.24288 & $-0.07454(0.01509)$ & 1.42559 & $0.00682(0.0$ \\
\hline Mianyang & $1.20449(0.12357)$ & $-0.06860(0.01551)$ & $1.47525(0.48889)$ & $0.00621(0.00671)$ \\
\hline Leshan & $1.00278(0.18374)$ & $-0.02812(0.02400)$ & $1.45204(0.58744)$ & $0.01040(0.00912)$ \\
\hline Yibin & $1.22467(0.07549)$ & $-0.05994(0.00886)$ & $1.01033(0.26825)$ & $0.02345(0.003$ \\
\hline Zhunyi & $1.02812(0.15233)$ & $-0.04181(0.01707)$ & $1.66949(0.54180)$ & $0.00546(0.007$ \\
\hline Kunming & $1.29812(0.09765)$ & $-0.07961(0.00928)$ & $1.15411(0.32471)$ & $0.01673(0.00477)$ \\
\hline Qujing & $1.01090(0.09477)$ & $0.00472(0.00972)$ & $0.80287(0.23916)$ & \\
\hline Xian & $0.91194(0.15942)$ & $-0.02331(0.01989)$ & $1.83181(0.58147)$ & $0.00560(0.00810)$ \\
\hline Xianyang & $1.32096(0.11358)$ & $-0.08111(0.01404)$ & $1.31693(0.41855)$ & $0.00975(0.00601)$ \\
\hline Lanzhou & $1.32395(0.10915)$ & $-0.08363(0.01299)$ & $1.26061 \quad(0.38527)$ & $0.01168(0.00556)$ \\
\hline Tianshui & $0.92866(0.17965)$ & $-0.02003(0.02373)$ & $1.55401 \quad(0.59639)$ & $0.00949(0.00901)$ \\
\hline Xining & $1.22287(0.12222)$ & $-0.07170(0.01539)$ & $1.45171(0.48052)$ & $0.00646(0.00658)$ \\
\hline
\end{tabular}

Notes: Estimated standard errors are in parentheses. 